Florida International University FIU Digital Commons

$11-21-1990$

\title{
Impact of nutrition education on knowledge and eating patterns in HIV-infected individuals
}

Patricia Boulos

Florida International University

DOI: $10.25148 /$ etd.FI14051808

Follow this and additional works at: https://digitalcommons.fiu.edu/etd

Part of the Dietetics and Clinical Nutrition Commons

\section{Recommended Citation}

Boulos, Patricia, "Impact of nutrition education on knowledge and eating patterns in HIV-infected individuals" (1990). FIU Electronic Theses and Dissertations. 1749.

https://digitalcommons.fiu.edu/etd/1749

This work is brought to you for free and open access by the University Graduate School at FIU Digital Commons. It has been accepted for inclusion in FIU Electronic Theses and Dissertations by an authorized administrator of FIU Digital Commons. For more information, please contact dcc@fiu.edu. 


\title{
FLORIDA INTERNATIONAL UNIVERSITY MIAMI, FLORIDA
}

Impact of Nutrition Education on Knowledge and Eating Patterns in HIV-Infected Individuals

\begin{abstract}
A thesis submitted in partial satisfaction of the requirements for the degree of Master of Science in Dietetics and Nutrition
\end{abstract}

by

Patricia Boulos

1990 
To Professors Katharine R. Curry, Evelyn B. Enrione, and Paulette Johnson:

This thesis, having been approved in respect to form and mechanical execution, is referred to you for judgement upon its substantial merit.

$$
\begin{aligned}
& \text { William J. Keppler } \\
& \text { College of Health }
\end{aligned}
$$

The thesis of Patricia Boulos is approved.

$$
\text { Evelyn B. Enrione }
$$

Paulette Johnson

$\overline{\text { Katharine R. Curry, Major Professor }}$

Date of Examination: November 21, 1990

Richard L. Campbell

Division of Graduate studies

Florida International University, 1990 
" [My mission is] to develop a vaccine, and before I die, to contribute to the cure of one or two other diseases. We know an awful lot about the AIDS virus, but we do not know enough... I do believe that we're going to get a vaccine against AIDS, and in this century. We need a vaccine fast because of two reasons: the drug addicts, they don't learn; and Africa, well, Africa is too big to learn. These are the real issues for the future of the epidemic because the gays have learned. "

Dr. Robert Gallo

National Cancer Institute Bethesda, Maryland 


\section{ACKNOWLEDGMENTS}

I would like to thank Katharine B. Curry, Ph.D., R.D., for her assistance and her constant positive reinforcement. Her expertise in teaching methodology, counseling, and human behavior was of great help. She was a listening advisor who, cheerfully and patiently, pushed me to give my best effort.

I would also like to thank Evelyn B. Enrione, Ph.D., R.D., for her valuable advice on the study design. She was always available to discuss the project and assisted in strengthening the thesis. I also owe her all my writing skills.

I am indebted to Paulette Johnson, Ph.D., for her assistance with the data analysis. Her humor made statistics interesting and fun.

Appreciation is expressed to Dale Nader, the Health Crisis Network, and all the participants in this study. They taught the real meaning of solidarity and cooperation.

Finally, particular thanks are due to Yolanda M. Ramirez, R.D., who supported me throughout the study. She encouraged me through the nutrition lectures and that can never be repaid. 
ACKNOWLEDGMENTS

LIST OF TABLES AND FIGURES . . . . . . . . . . . . . . vii

I. STATEMENT OF THE PROBLEM . . . . . . . . . . . . . 1

Statement of the hypotheses ........ . 3

Limitations of the study. . . . . . . . . 3

II. RELATED LITERATURE . . . . . . . . . . . . . 5

Review of the literature . . . . . . . . 5

Pathology of AIDS . . . . . . . . . . 6

Effects of HIV-Infection on Nutritional

Status . . . . . . . . . . . . . . 7

Effects of malnutrition on immunity. . . . 11

Efficacy of nutrition education . . . . . 14

III. METHODS AND PROCEDURE. . . . . . . . . . . . . 17

setting. . . . . . . . . . . . . . . . 17

Subjects . . . . . . . . . . . . . 17

Procedure. . . . . . . . . . . . . 18

Instruments. . . . . . . . . . . . . 18

Nutrition lectures . . . . . . . . . . 23

Teaching methods . . . . . . . . . 26

Data analysis. . . . . . . . . . . 27

IV. RESULTS AND DISCUSSION . . . . . . . . . . . 31

Results. . . . . . . . . . . . . . 31

Knowledge level . . . . . . . . . . . 32

Nutrient intake . . . . . . . . . . . . 38 
Discussion . . . . . . . . . . . . . 46

Nutrition knowledge . . . . . . . . . . . 46

Population size... . . . . . . . . . . 48

Nutrient intake . . . . . . . . . . . . . . 49

vulnerability to nutrition fraud. . . . . 50

V. SUMMARY CONCLUSIONS AND RECOMMENDATIONS. . . . . . 53 REFERENCES • • . • . . . . . . . . . . . . . 55 APPENDICES . . . . . . . . . . . . . . . . . 64

Appendix A . . . . . . . . . . . . 64

Appendix B . . . . . . . . . . . 65

Appendix C . . . . . . . . . . . . 69

Appendix D . . . . . . . . . . . . . 78

Appendix E . . . . . . . . . . . . . . 79 


\section{LIST OF TABLES}

Table 1. Timetable . . . . . . . . . . . . . . 19

Table 2. Mean Dietary Intakes of Energy Yielding

Nutrients and Cholesterol, by Day and by Group . . .40

Table 3. Mean Dietary Intakes of Minerals, by Day and by Group . . . . . . . . . . . . . . .41

Table 4. Mean Dietary Intakes of Vitamins, by Day and by Group . . . . . . . . . . . . . . . .42

Table 5. Mean Dietary Intakes on Day A. Significance of a Difference in Intakes, Between Groups . . . . .44

Table 6. Significance of a Difference in Nutrient Intakes, From Day A to Day B (B-A) and From Day B to Day C $(\mathrm{C}-\mathrm{B})$, Between Groups . . . . . . .46

\section{LIST OF FIGURES}

Figure 1. Types of HIV Infection. . . . . . . . . . 8

Figure 2. Mean Percentage of Total Questions Answered. . . .33

Figure 3. Mean Percentage of Total Questions Correctly Answered . . . . . . . . . . . . .33

Figure 4. Mean Percentage of Answered Questions Correctly Answered 34 


\section{Chapter one \\ statement of the Problem}

Acquired Immune Deficiency Syndrome (AIDS) and impaired or threatened nutritional status seem to be closely related. It is now known that AIDS results in many nutritional disorders including anorexia, vomiting, protein-energy malnutrition (PEM), nutrient deficiencies, and gastrointestinal, renal, and hepatic dysfunction $(1-7,8)$.

Reversibly, nutritional status may also have an impact on the development of AIDS among HIV-infected people. Not all individuals who have tested antibody positive for the Human Immunodeficiency Virus (HIV) have developed AIDS or have even shown clinical symptoms $(9,10)$. A poor nutritional status, especially PEM, has a depressing effect on immunity which may predispose an individual to infection (11). It has been proposed that a qualitatively or quantitatively deficient diet could be among the factors precipitating the transition from HIV-positive to $\operatorname{AIDS}(12,13)$.

The interrelationship between nutrition and AIDS reveals the importance of having a multidisciplinary health care team approach to treatment (11), including having a registered dietitian on the medical team. With regards to alimentation, the main responsibility of a dietitian is to inform the public concerning sound nutritional practices and encourage healthy food habits 
(14). In individuals with inadequate nutritional behavior, a positive, long-term change has been seen when nutrition education tailored to specific physiological and emotional needs was provided along with psychological support through counseling (14). This has been the case for patients with various illnesses and may also be true in AIDS patients as well.

Nutritional education specifically tailored for each AIDS patient could benefit the patient by improving the quality of life and preventing or minimizing weight loss and malnutrition (15-17). Also, it may influence the progression of the disease by delaying the onset of the most severe symptoms and increasing the efficacy of medical treatment $(18,19)$.

Several studies have contributed to a dietary rationale for nutritional intervention in HIV-infected and AIDS patients $(2,4$, 20-25). Prospective, randomized clinical research in AIDS patients have not yet been published to support this dietary rationale; however, isolated case reports show its suitability (3). Furthermore, only nutrition intervention as applied by a medical team in an institution or hospital has been evaluated. Research is lacking concerning the evaluation of nutritional education of either non-institutionalized or hospitalized groups of persons who are managing their own food choice and intake.

This study compares nutrition knowledge and food intakes in HIV-infected individuals prior to and following nutrition education. It was anticipated that education would increase the 
knowledge of nutritional care of AIDS patients and lead to better implementation of nutrition education programs.

\section{statement of the Hypotheses}

The hypotheses for this study were the following:

* The subjects in the experimental group will increase their scores on the nutrition knowledge questionnaire after nutrition education while that knowledge will remain unchanged in the control group.

* The subjects in the experimental group will increase their total kilocalories and protein intakes while these intakes will remain unchanged or will decrease in the control group.

* The number of subjects taking vitamin and mineral supplements will increase in the experimental group while it will remain unchanged or will decrease in the control group.

* The number of subjects willing to try a fad diet will decrease in the experimental group while it will remain unchanged or will increase in the control group.

\section{Limitations of the study}

1. Participants were obtained from a population of convenience: all were members of the same network, the Health Crisis Network. These are people that are concerned and attempting to solve their problems. Thus, it is possible that these subjects may not represent the general HIV-infected population.

2. The sample sizes for this study were small. Therefore, results can not be extrapolated to the general HIV-infected population. 
3. The study was conducted within a short period of time (two months). Changes in knowledge and, even more so, in intakes may have been more significant had the study been performed over a longer time span.

4. The questionnaire used in this study was administered for the first time without prior validation. Some questions may have been more difficult or easier than others, thus influencing the final scores of each subject.

5. The number of nutrition lectures was limited to four in order to obtain optimal participation and minimal drop-outs. Ideally, more lectures should have been organized to provide a more thorough education to all subjects. 


\section{Chapter Two:}

\section{Related Literature}

AIDS is the most researched disease in history $(26,27)$. The worldwide effort is well illustrated by the abundance of studies undertaken and the number of scientific articles published, reaching 500 per month (26). As a result, in the brief span of two years, AIDs has been well documented clinically, epidemiologically, and immunologically, although no cure has been discovered up to now. Some of the literature published is reviewed from a nutrition point of view in this chapter.

Review of the Literature

Since the early 1980's when AIDS became a major health issue, more than 133,000 adults/adolescents cases have been reported in the U.S. Of these cases, at least 81,000 have died $(16,28,29)$ according to the statistics from the World Health Organization (WHO) and the centers for Disease control (CDC). Worldwide, 53\% of reported AIDS cases belong to the U.S.A. (29).

The case rate in 1988 for AIDS in the U.S. was 12.4 reported cases/100,000 population which is among the highest rate in the world. This rate is much lower in other countries, being below $6 / 100,000$ in all European countries for example (29).

Predictions state figure as high as 365,000 cumulative cases to be diagnosed by the end of 1992 (30). In 1987, the CDC proposed a new reporting definition of AIDS which included weight 
loss as a symptom (31). As a result, 20,620 new cases of AIDS were reported in the U.S. representing a 58\% increase over 1985 (28).

\section{Pathology of AIDS}

AIDS is caused by the human immunodefiency virus $(26,27$, $32,33)$. HIV is a lentivirus; it causes a disease characterized by a long incubation period, persistent infections, and an impairment of the immune system (27). In addition, as most viruses, HIV has a specificity for host cells, mainly leukocytes which is a further jeopardy to the immune system as leukocytes act as scavengers helping to fight infection. More specifically, host cells include mainly T-helper-lymphocytes but also monocytes, macrophages, brain cells, certain epithelial cells, and cells that line the intestinal mucosa (27).

once the HIV enters a host cell, its RNA is transcribed into a DNA that is integrated into the host cell's DNA. Permanent infection is established when the viral DNA and the host cell DNA duplicate together every time the cell divides. The course of the disease depends on the kind of cell infected, and more precisely, on its speed of replication (27).

In monocytes and macrophages, the HIV grows slowly but continuously, altering the function of these cells. The virus can remain dormant indefinitely in T-lymphocytes. This is the latent stage of the disease. However, once the infected T-lym 
phocytes are stimulated, the virus rapid replication causes the host cell to burst. Released HIV infect surrounding T-lymphocytes and the cyclic process proceeds (27).

In summary, HIV infection results in a depletion of lymphocytes and, therefore, in immunodeficiency and the collapse of a major defense mechanism of the host. As a result, the host is defenselessly exposed to any opportunistic infectious agent.

\section{Effects of HIV-Infection on Nutritional status}

There are four stages in the disease process which starts with the HIV infection (Group I) followed by an asymptomatic infection (Group II). Symptoms begin to appear with generalized lymphadenopathy (Group III) which usually deteriorates into the AIDS stage (Group IV), also called full-blown AIDS (26) (Fig.1). Nutritional complications appear in the AIDS stage as (a) constitutional symptoms (unexplained fever and/or diarrhea for more than a month, involuntary weight loss exceeding $10 \%$ of body weight); (b) neurological disease (impairment of fine movements including those needed for feeding, dementia, depression); and (c) secondary infection diseases (diarrhea, fever, localized gastrointestinal manifestations) $(25,33-36)$.

Almost all individuals diagnosed with AIDS present serious symptoms causing nutritional disorders that lead to weight loss (34). Weight loss can result from factors as diarrhea, nausea, vomiting, malabsorption, decreased appetite, increased and unmet nutritional needs, and vitamin and mineral deficiencies or it can 
be unexplained (34). Emotional stress and economic restraints may also limit food intake in persons with AIDS (PWA) (37).

Figure 1. Types of HIV infection.

Group I. Acute Infection

Transient signs and symptoms

Group II. Asymptomatic Infection

Group III. Generalized Lymphadenopathy

Palpable, lasts more than 3 months

Group IV. AIDS

Symptoms can be classified into one or more of the subgroups below:

Subgroup A. Constitutional Disease

Fever for more than a month; involuntary weight loss of more than $10 \%$ of body weight; diarrhea for more than a month

Subgroup B. Neurological Disease

Dementia; peripheral neuropathy

Subgroup C. Secondary Infections

Pneumocystis carinii pneumonia, candidiasis of oesophagus, CMV infection, oral thrush

Subgroup D. Secondary Cancers

Kaposi's sarcoma, non-Hodgkin's lymphoma, primary lymphoma of the brain

Subgroup E. Other conditions with HIV infection

References:

1. Centers for Disease Control: Classification system for human lymphotropic virus type III / lymphadenopathy-associated virus infections. MMWR 35:334-339, 1986.

2. Centers for Disease Control: revision of the CDC Surveillance Case Definition for Acquired Immunodeficiency syndrome. MMWR $36: 1 S$, 1987 . 
Patients with AIDS were reported to be underweight and depleted of potassium $(p<0.001)$ with the lowest values occurring near death (38). In these persons, intracellular water volumes were decreased $(p<0.001)$ as well as body fat contents and serum protein concentrations (38).

Wasting is a continuous process in all patients that may occur at any time during the course of the disease (38). Extreme degrees of wasting can be seen at autopsy (38). Kotler et al. (38) suggested that timing of death from wasting in AIDS is related to the degree of tissue depletion and is not dependent on the underlying cause of wasting. As a result, they proposed that a successful attempt to maintain body cell mass would prolong survival in patients with AIDS.

The gastrointestinal tract can be severely affected by infections $(2,5,39)$. Esophageal candidiasis is the most common cause of such symptoms as dysphagia (40). Contamination of the upper small intestine may be the cause of weight loss due to diarrhea and malabsorption (41). Diarrhea is more prevalent in patients with gastrointestinal infections $(5,36)$. Most patients with malabsorption show an increased number of aerobic bacteria in their jejunal fluid (42). In their cases, it is believed that specific therapy can lead to a symptomatic improvement (43). Also, diarrhea occurs in $25 \%$ of patients in an unexplained fashion $(36,43,44)$, although $\mathrm{Smith}$ et al. suspect that percentage to be reducible with thorough diagnostic evaluation (43). 
The increased occurrence of enteric infections can be explained by an alteration in mucosal immunity. Budhraja et al. found that PWA had an increase in T-cell population in their duodenal mucosa parallel to that seen in their blood (41). Possibly justifying the increased rate of intestinal infections is the fact that homosexual males, a population at high risk for AIDS, are further exposed to enteric pathogens because of their sexual practices (gay bowel) (44-46). Protozoa (Giardia lamblia, Entamoeba histolytica) bacteria (salmonellas, shigellas, campylobacter) and viruses (CMV, herpes simplex, hepatitis $A$ and $B$ ) are more prevalent in the homosexual and bisexual population than in the general population $(46-48)$.

Some therapeutic agents have a severe impact on the nutritional status of AIDS patients, often resulting in symptoms that limit food intake. Chemotherapies for Kaposi's sarcoma and lymphomas or antibiotics produce severe nausea, vomiting, anorexia, stomatitis, and dry mouth (20). Other drugs cause, in addition to these symptoms, metallic taste, diarrhea, tongue tenderness, mouth pain, and epigastric pain. Nausea and taste alterations might be encountered in patients receiving azidothymidine (AZT) (20). Isoniazid, an antibiotic, causes imbalances in pyridoxine and vitamin B12 levels (20). More debilitating nutritional complications can result from the prolonged treatment of Pneumocystis carinii pneumonia with pentamidine leading to hypoglycemia and occasionally diabetes and pancreatitis (49). It was found 
that $90 \%$ of AIDS patients were ingesting at least one potentially hepatotoxic drug (50). Although liver failure was not believed to contribute to the death of any patient, it is very likely that liver damage impaired their nutritional status.

Renal disease is also frequently found in PWA (8). The disorder most often encountered has been termed HIV-associated nephropathy and is characterized by proteinuria and renal failure $(51-53)$.

\section{Effects of Malnutrition on Immunity}

Over the years, research has shown the negative effect of malnutrition on the immune system and the increased vulnerability of malnourished individuals to their environment $(11,54,55)$.

Many of the clinical symptoms seen in the AIDS stage are commonly observed in malnourished individuals: apathy and decreased ability to socialize, concentrate, and exist independently (56). Common physiological symptoms include generalized impairment of the immune function along with other vital bodily functions. In fact, depletion of body cell mass limits the providence of necessary compounds for an immune response (57) and more generally for basic life support (58).

More specifically, PEM and/or nutritional deficiencies have effects on the immune system similar to those seen in PWA: decreased total count of $\mathrm{T}-1$ ymphocytes (helper and suppressor cells); impaired cell mediated immunity (55); impaired secretory immunity (59); defects in phagocytic functions (60); and de- 
creased killer cell activity (61).

Because of decreased resistance, malnourished people suffer from multiple opportunistic infections which can modulate humoral and/or cellular immunity and cause immunosuppression (13). Deficiencies in specific nutrients i.e., iron, zinc, vitamins $A, C$, E, pyridoxine, or folate can also result in defects in the immune function $(54,11)$. Animal studies confirm these findings. For instance, a decreased blood clearance rate of injected Escherichia coli as well as a decrease in the phagocytic activity of leukocytes was found in vitamin A deficient rats (62). Also, vitamin A deficiency in mice resulted in decreased antibody responses to protein antigens (63). Nutritional stress, such as deficiencies or malnutrition, because of its impact on cellular immunity, could accelerate the development of AIDS, namely the transition from the asymptomatic stage to the AIDS stage $(1,12)$. It was hypothesized that PEM and repeated assault to the immune system by multiple infections may be cofactors of HIV infection which may lead to profound immunodeficiency and AIDS (13). However, studies are lacking to verify this hypothesis.

That an impaired immune system in PWA could withstand certain environmental pathogens if the individual was not malnourished is conceivable. As cell mediated immunity is defective in PWA, it is reasonable to attempt to avoid any further nutritional deficiencies that can impair the immune system.

A great number of non-scientific nutritional interventions 
have been proposed to treat or even cure AIDS $(64,65)$. More traditionally, many special diets and products have been studied $(66,67)$. However, a nutritional intervention has never been documented to reverse the disease process (68).

Nevertheless, sound nutritional intervention in PWA presents some benefits $(20,23,25,69)$. Intervention consists of promoting adequate and balanced nutrition for weight maintenance and prevention of vitamin and mineral deficiencies during the asymptomatic stages $(20,21,70)$. In later stages, intervention is oriented towards the alleviation of specific disorders experienced and the increase of the patients comfort $(17,24,69,71)$. Enteral and parenteral nutrition become very useful when adapted to specific needs and concomitant disorders, i.e., anorexia, diarrhea, dehydration, anemia, and vitamin or mineral deficiencies $(23,25)$. Short term total parenteral nutrition can be useful for people receiving new treating agents causing side effects such as nausea, vomiting, and anorexia or when acute infection is experienced (72). Kotler et al. (38) stated that the approach to nutritional therapy should be the same in AIDS patients as in any other chronic, progressively debilitating illness. They advocated an aggressive diagnosis and treatment of nutritional problems as a way to provide a "reasonable expectation for some prolongation of comfortable and productive life" in PWA. However, the ability of nutritional support to replete body cell mass is still to be established. Studies did not demon- 
strate tissue repletion in PWA, despite apparent clinical stability (38). Obviously, every AIDS patient should not automatically receive total parenteral nutrition. In fact, with a deteriorating clinical picture, parenteral nutrition does not alter the course of the disease and may increase mortality and morbidity secondary to the complications of intravenous route of alimentation, especially in a weakened person $(73,74)$.

A consistency in methods of nutritional support in AIDS only appeared in 1989 following the work of the Task Force on Nutrition support in AIDS $(69,71)$. They recommend a thorough nutritional assessment of all HIV positive diagnosed individuals and emphasized the essentiality of nutritional support as part of the medical management of AIDS patients. They also advocated nutrition education to all HIV infected individuals. The American Dietetic Association published a position paper in June, 1989 (16) encouraging not only nutritional intervention but also education as part of the overall care provided at all stages of the disease and stressed the need for nutrition research. Comparable statements were issued by the American Public Health Association (75). Several studies, reviewed above, have been published supporting the efficiency of nutritional intervention but studies examining the impact of nutrition education on eating patterns of PWA are lacking. However, one can reasonably assume that results would be comparable to the impact of educational programs designed for other chronic illnesses. 


\section{Efficacy of Nutrition Education}

The California Expanded Food and Nutrition Education Program (EFNEP) has been evaluated using data from 24-hr. food recall from individuals with various illnesses, not including HIVinfection (76). Starting with similar EFNEP and control groups, a significant improvement in nutrient intake for the EFNEP group was shown after six months of instruction while no change occurred in the control group. Many factors were found to have led to changes in eating behavior: the length of nutrition education sessions, the number of sessions, and the topics presented. Overall, the program was effective in producing significant improvement in the eating habits of the subjects (76). Similar studies of the EFNEP were undertaken by other researchers, resulting in the same conclusions $(77,78)$. Amstutz and Dixon (78) found significant, long-term changes in the EFNEP group in comparison with the control group.

Other programs were more specifically targeted toward severe, chronic diseases such as coronary heart disease, cancer, osteoporosis, or obesity in adults (79). Six sessions were offered to each of these groups in the form of lectures supported by a wide variety of printed and audiovisual teaching aids as well as group discussion, games, and food tasting. The impact of the program was evaluated using food frequency records. Results indicated that participants made significant changes in their food intakes i.e., a decrease in high fat cheeses, red meats, 
desserts, sodium-rich foods, tea, and coffee consumption $(p<0.05)$ and an increase in low-fat dairy products intake $(p<0.05)$, showing again the efficacy of nutrition education. Acknowledging the success of such educational programs, this study was designed to determine whether an increase in knowledge subsequent to nutrition education would lead to a self-implemented change in eating habits in HIV-infected individuals. 


\section{Chapter Three:}

\section{Methods and Procedure}

\section{setting}

Research took place at the Health crisis Network (HCN) in

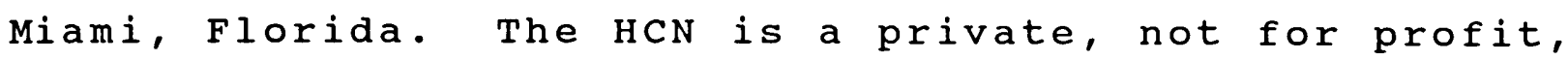
community-based organization in Dade county. It was created in 1983 with specific goals that address problems resulting from AIDS. Support groups meet weekly and reflect on needs of HCN's client population. Counseling is offered to help clients cope with the physical, situational, and/or environmental stress i.e., terminal illness, community rejection, isolation, family reaction, risk reduction, adaptation, health care institutions, financial jeopardy, role changes, death and dying.

\section{subjects}

The subjects were clients of the $\mathrm{HCN}$ enrolled in group support sessions taking place on Wednesdays (a PWA Support Group) and Thursdays (a HIV + 6 week Psycho Educational Program and two outpatient Addiction/HIV Program, continuing Care Groups). The research protocol and goals were announced two weeks prior to the first nutrition lecture in all Wednesdays and Thursdays groups. Clients were asked to volunteer in participating in the study as experimental or control group. It was announced that nutrition lectures would be made available on demand to individuals accepting to enroll in the control group once results of the 
research was obtained.

\section{Procedure}

The study was designed to obtain information over two months about the nutrition knowledge and eating patterns of people infected with HIV. For that, two groups of volunteers were formed; an experimental group who received nutrition education and a control group who did not receive nutrition knowledge. Members of the experimental group volunteered to attend a nutrition lecture which lasted approximately twenty minutes each week, for four weeks. They were asked to come an hour prior to their regular meeting time for four weeks, and once a month later. Participants in both groups were to complete a 24-hour recall and a questionnaire on three different days: before any lecture took place (Day A), following the fourth lecture (Day B), and a month after the fourth lecture (Day C) (Table 1). Members of the experimental group completed the forms on site while those of the control group completed the forms at their own convenience and returned them the following week.

\section{Instruments}

The instruments included recalls of 24 -hour food intake, a questionnaire on nutrition knowledge, and lesson plans.

The 24-hr. food intake recall consisted of recording the specific food items eaten by an individual during 24 hours. Recalls detailed the preparation and amount of each food item ingested (80) (Appendix A). The handout included information 
explaining the way to complete the recall and the specific data needed. The lecturer was available for additional help for completion of the recall. Recalls of $24-\mathrm{hr}$. intakes have been repeatedly used in group studies $(81,82)$. The choice of a method must be adapted to (a) the objective of the study (degree of accuracy required), (b) the study population (sample size, cooperation, schedule flexibility, age, sex), and (c) the resources available (manpower, financial constraints, data base adequacy) •

\section{Table 1. Timetable}

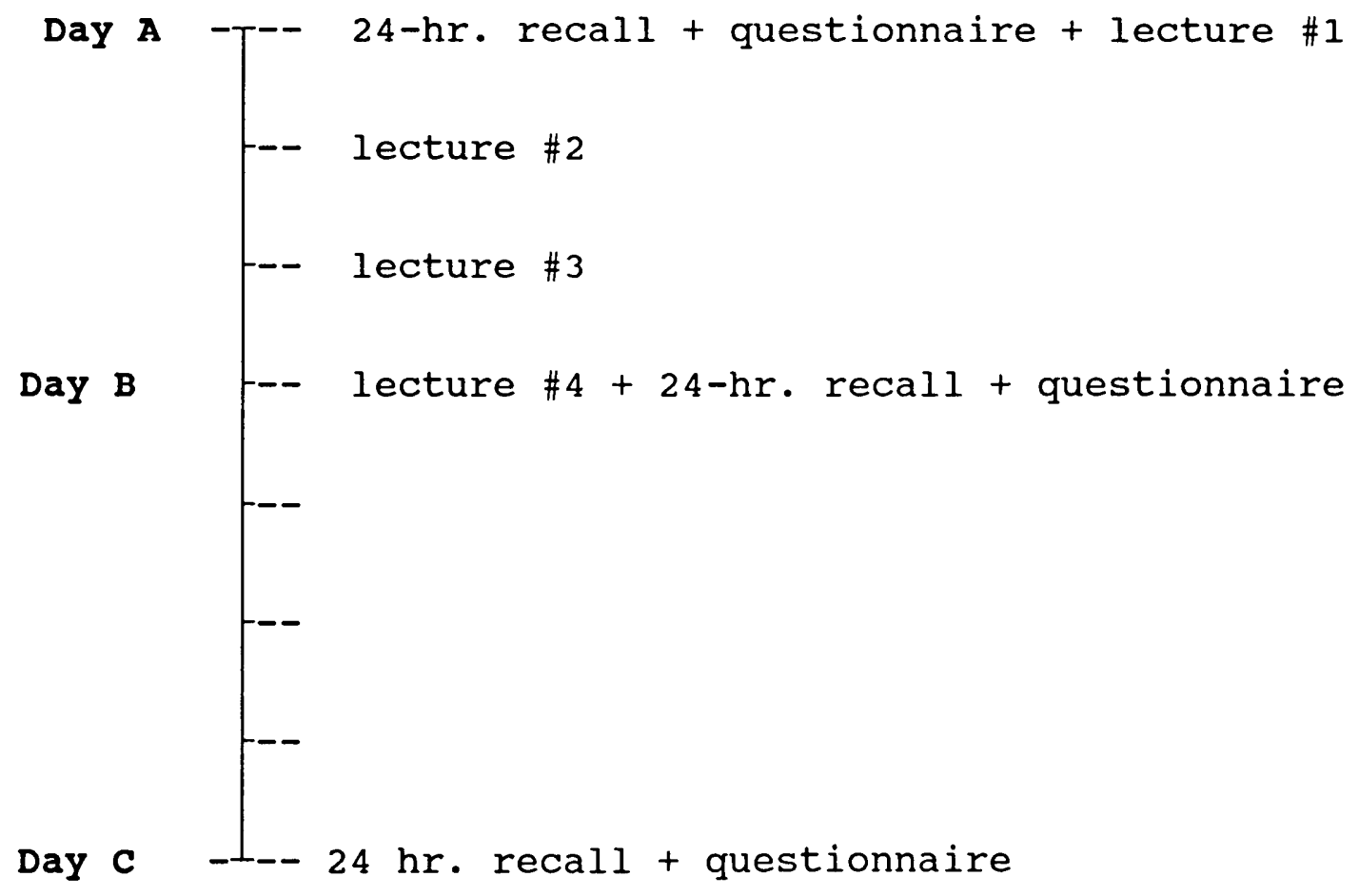


Young et al. (83) were the first to question the validity of the 24-hr. recall when used for research on grade school students, high school and college students, and pregnant women. In a comparison of dietary study methods, they showed that the $24-\mathrm{hr}$. recall yielded the same estimate of the mean intake of a group as other methods, although that was not so on an individual basis. Others reached the same conclusion when studying lactating women (84), adolescent females (85), and general populations (86-88). Also, it has been reported that $24-\mathrm{hr}$. recalls yield results comparable to those from 7-day record for group comparisons of mean intakes (89).

One of the disadvantages in using $24-\mathrm{hr}$. recalls lies in the flat slope syndrome described as the tendency of participants to overestimate intake when it is low and to underestimate it when it is high (84). Studying recalls which were compared to the actual food eaten by elderly people (90), differing conclusions were reached depending on the statistical test applied to the data. Using regression analysis, the flat slope syndrome was marked $(p<0.5)$ for calories, protein, and vitamin A. Thus, for these three nutrients, the $24-\mathrm{hr}$. recall would be "conservative" for group comparisons: it would rarely indicate a difference in intake where no difference exists; however, it could indicate a non-significant difference between intake recalled and actual intake where there is a significant difference. When using paired t-tests, as in this study, there were no significant 
differences between recalled and actual intakes, except for calories.

The validity of the $24-\mathrm{hr}$. recall also varies according to the sex and age of the population examined. Karvetti and Knuts (88) studied 140 subjects of both sex, $15-57$ years old, and found that recalls from women were more accurate than those from men probably because women are used for estimating amounts and portion sizes, a result confirmed by Karkeck at al. (91). They also reported that recalls from the 35-44 age group were the most accurate, maybe because they were more interested in the study. Interestingly, the population examined in this study is of similar age range.

Another disadvantage of a $24-\mathrm{hr}$. recall, especially when self-administered, is the frequent omission of food items. It has been repeatedly reported that these omissions are common even on recall of foods eaten less than seven days previously $(85,88$, 92-94). Also, items that are consumed less often are more susceptible to be omitted on the recall (88). Studies revealed that most omission were found in recalls of women (95), older people, and children accompanied by a parent (91); all populations that were not included in this study.

Supported by many studies results $(89-91,95)$, it can be assumed that recalls obtained here were of optimal accuracy and that record keeping over a longer period of time was not necessary. In addition, paired t-test were used so that the flat slope 
syndrome would be avoided. However, it was not anticipated that the groups involved would be so small.

For more accurate results, Balkogh et al. (96) recommend the repetition of $24-\mathrm{hr}$. recall before classifying dietary intakes, especially in populations for which the range of variability is not extreme. However, this guideline was not followed in this study for practical reasons and to limit dropouts. Overall, 24hr. recalls were estimated to be appropriate for this study.

The questionnaire on nutrition knowledge consisted of thirty true/false questions all derived from material discussed during the nutrition lectures (Appendix B). The questions could be classified into two categories: 14 questions on beliefs (\#1-3; $9-18,20)$ and 16 questions on practical knowledge (\#4-8, 19, 21-30). Questions regarding beliefs about food covered aspects of the nutritional care for which the scientific community has proposed some recommendations. The participants were asked if they believed that their diet had any influence on the disease (\#1-3, 14); that some foods can be dangerous (\#15) or strengthening their immune system (\#16); or that some unproven diets are worth being tried or are beneficial (\#9-12). Questions on practical aspects of nutrition tested the knowledge on the increased needs in various nutrients $(\# 4-6)$; the special needs of vegetarian individuals (\#8); the ways of limiting food contamination (\#19) and nutrient loss (\#25-30); adequate vegetable protein 
combinations (\#21); food density (\#23); or feeding frequency (\#7, $24)$.

The lesson plans were designed to yield to four lessons of twenty minutes. The topics were chosen to best serve the population taught. They briefly discussed all nutrient groups and then developed aspects of interest to HIV-infected individuals.

\section{Nutrition Lectures}

The nutrition lectures were designed to expose the audience to the general nutrition guidelines and recommendations developed for individuals with AIDS and to explain the rationale for these recommendations.

Participation in the nutrition lectures meant that each subject agreed to donate some of their free time. As most members had a full-time job and/or had limited transportation means, the number of lectures was limited to four. They were asked to come an hour prior their regular meeting time, five times; this limited their time investment to five hours. It was thought that enrollment would have been less important and the drop-out greater if subjects were asked to volunteer more time to the study.

All lectures were given within the hour preceding support group meetings. Attendance was verified at each session. Lessons were planned to present the following topics (Appendix C):

1. "Good" Nutrition for HIV-Infected People.

2. Nutrient Needs for HIV-Infected Individuals. 
3. Specific Problems and Solutions Encountered in the HIVInfected Individual.

4. Meal Planning and Food Preparation.

Nutrition Lecture 1: "Good" Nutrition for HIV-infected people.

After strongly communicating that nutrition is not a cure for AIDS, the objectives of nutritional care in an HIV-infected population were stated. The function of major nutrient groups were generally discussed (energy, protein, carbohydrates, fat, alcohol, vitamins, and minerals). Finally, the essential nutritional recommendations for HIV-infected individuals were exposed, i.e. increase the intake of energy, protein, vitamins and minerals; alleviate any discomfort; and individualize each nutritional care plan.

The lecture was supported with numerous overhead transparencies that summarized the main points discussed. The advantage of the transparencies is that the lecturer can face the audience while using the projection (14). As this first lecture introduced the participants to nutrition and also because of time constraints, participation was kept to a minimum. The session lasted an hour of which 40 minutes were devoted to the completion of forms.

Nutrition Lecture 2. Nutrient Needs for HIV-Infected Individuals. This lesson detailed the recommendations stated in the previous lecture so that they would be reinforced. The subjects learned the reasons for and ways of meeting the increased needs 
of calories, protein, vitamins, and minerals. Teaching aids included overhead transparencies and handouts that summarized the lecture so that subjects would listen instead of taking notes. Also, handouts are a permanent record of the material presented that subjects can take home for further reference or review (14). Participation was encouraged; volunteers could calculate their personal approximate needs in calories and protein and compare them to the needs of a similar individual who would not be infected. Also, the audience was asked for suggestions for examples of dense foods which were added to a list projected. Samples of supplements, protein powders and vitamins and/or minerals were brought and compared with great interest (Appendix D) . The reading of label (ingredients list and nutritional information) was briefly discussed; more details were provided on a handout.

Due to the great interaction of the group and the numerous questions generated, the session lasted for an hour only interrupted because of schedule restrictions.

Nutrition Lecture 3. Specific Problems and Solutions Encountered in the HIV-Infected Individual.

Nutritional disorders classified into three categories (decreased intake, increased needs, and decreased absorption/utilization) were discussed. Numerous overhead transparencies supported the lecture/discussion. Subjects shared techniques for alleviating specific symptoms. 
Also, the delicate topic of unproven nutritional therapies, faddishness, and quackery was discussed. Again, handouts were distributed and the audience volunteered and requested information. The session lasted an hour as the audience was eager to obtain the most information on these alleviating techniques.

Nutrition Lecture 4. Meal Planning and Food Preparation.

Techniques for meal planning and for limiting nutrient loss and food contamination were explained. Many examples were given. Scenarios were proposed in which the audience were to determine the technical defects. Assertive behaviors in situations encountered when eating out were discussed. Some techniques were suggested by participants.

This last lecture only lasted 40 minutes as time was required for completing the second set of $24-\mathrm{hr}$. recall and questionnaire.

Teaching Methods

Teaching techniques should meet the objective of having the students comprehend, acquire, and retain valid nutrition information (14). To achieve this, the teacher has to consider the setting, the number of students, their interest in nutrition, and the topics to emphasize in the teaching (97). In this study, the classroom was of medium size. A small group of subjects was expected to enroll; however, their participation in itself reflected a certain interest in nutrition.

For basic nutrition information, lecturing was the method 
chosen. Lectures allowed a clear presentation of technical information, especially as time was limited (14). Most other methods lead to more learning than a lecture does. To palliate to this inconvenience, many visual aids, i.e., overhead transparencies, food samples, and handouts, were used to keep the audience's attention and enhance learning.

Better results are achieved when students are actively involved (98). The small size of the group permitted frequent discussions. In fact, as discussion requires interaction among participants, it is almost impossible with a large group (99). To create a favorable physical environment, chairs were arranged in a circle and subjects sat close to one another so that they could interact without having to raise their voice. The discussions led the participants to share points of views, knowledge, and concerns with their peers. They could become aware of similarities and differences among them which is the goal of a discussion (14). An open discussion also facilitated the generation of questions for which the answer were immediately given and probably better assimilated. Finally, each participant realized he was not an isolated case, that other people shared similar problems and might offer valuable information and experience.

\section{Data Analysis}

The 24-hr. recalls were entered in a computerized system using Computrition, a nutritional analysis software. The information of each individual were entered separately as well as the 
average recommended intake for energy (23 kcal/lb ABW) and protein $(0.7 \mathrm{~g} / 1 \mathrm{~b} \mathrm{ABW})$ (17) .

The computer analysis provided a display of the content of each day's intake in energy and 19 nutrients (Appendix E). This intake was compared to the entered individualized recommendation for energy and protein intake and to the Recommended Dietary Allowances (RDA) as revised by the National Research Council in 1989 for the remaining nutrients (100).

Each questionnaire was graded using a key. Each question was worth one point. A perfect score is 30 points $(100 \%)$.

Five values were derived from the questionnaire results:

1. total number of questions answered.

2. percentage of total questions answered.

3. number of questions answered correctly.

4. percentage of total questions answered correctly.

5. percentage of answered questions answered correctly.

An increase in the total number of questions answered indicated that the participants were more confident in their knowledge.

The percentage of total questions answered (PTQA) was computed as follows:

$\operatorname{PTQA}(\%)=\frac{\text { number of questions answered }}{\text { total number of questions }(30)} \times 100$ 
As the preceding parameter, it reflected the confidence level of the participants in their knowledge, in a percent unit which was easier to interpret.

The number of questions answered correctly was the score obtained by participants. It indicated the adequacy of their knowledge. Any improvement in that score reflected a learning process.

The percentage of total questions answered correctly (PTQAC) was obtained as follows:

$$
\text { PTQAC }=\frac{\text { number of questions answered correctly }}{\text { total number of questions (30) }} \times 100
$$

A variation in this parameter indicated a change in knowledge level, either as a gain or loss of knowledge. The disadvantage with this value was that it depended on the level of confidence of the participants in their knowledge. For instance, a person who answered fewer questions automatically had a low PTQAC, while those who answered all questions had a better chance to have a high PTQAC. As a result, this percentage did not reflect purely knowledge.

This was avoided when using the percentage of answered questions answered correctly (PAQAC) which was obtained by the following formula: PAQAC $(\%)=\frac{\text { number of questions answered correctly }}{\text { number of questions answered }} \times 100$ 
This parameter also measured the knowledge level and its variation. However, it yielded a more accurate measure as only the questions answered were taken into consideration.

All three sets of forms from the control group were analyzed. In the experimental group, data was collected and analyzed from the subjects who were present at at least three of the four lectures and who had completed all three sets of forms.

Paired $t$-tests and independent sample $t$-tests were performed to determine the significance of a change in nutrition knowledge and/or nutrient intake within groups and between groups. Data were analyzed to determine knowledge level and mean intake variation of each group and make "before/after" and "after/one month later" nutrition education comparison within groups and between groups.

Questionnaires were analyzed as to which questions were most commonly answered correctly and which were not. Also, it was examined whether questions commonly answered wrongly on day $A$ were answered correctly on days $B$ or $C$, to determine whether knowledge increased. 


\section{Chapter Four:}

\section{Results and Discussion}

\section{Results}

No one volunteered in the Wednesday group. From the Thursday groups, three persons volunteered to be in the control group and 10 in the experimental group. overall, only five volunteers attended three of the four lectures which was a requirement for eligibility. of these, one individual was excluded from the analysis as he was institutionalized and therefore had little control over his intake.

As a result, the experimental group consisted of four white males, age range 31 to 45 years old (mean $=39.25$ ). Two of them lived alone. They all usually ate at home where they cooked for themselves, two of them enjoyed this activity. Members estimated their activity level to be moderate to high. only one of them had had a nutrition class two years prior and that person was the only one to restrict his diet because of food allergies. They estimated their diet to be poor $(n=2)$ or average $(n=2)$.

The control group consisted of three males, 35-46 years old (mean $=42.33)$, two White and one Hispanic. All usually ate at home where two of them prepared their meals. One individual followed a low fat diet advised by his physician $(3,000 \mathrm{kcal} / \mathrm{d}$; 7-8 oz protein food/d; fat not determined). This individual was the only one to have had nutrition classes before. They estimated 
their intake to be average $(n=2)$ or good $(n=1)$.

All individuals were HIV-infected, currently experiencing various stages of the disease.

\section{Knowledge Level}

The experimental group did not significantly differ from the control group regarding nutritional knowledge on day $A$. The experimental group correctly answered $70 \%$ of the 30 questions (control, 64\%). A more informative figure was the percentage of answered questions that were correctly answered: $76 \%$ for the experimental group and $74 \%$ for the control group.

Percentage of Total Questions Answered (Fig. 2)

In the experimental group, the percentage of total questions answered increased from $91 \pm 10 \%$ on day $A$ to $99 \pm 2 \%$ on days $B$ and $c$, although this increase was not significant $(p>0.1)$.

In the control group, the initial value was of $87 \pm 12 \%$, this value increased to $90 \pm 10 \%$ on day $B$ and then decreased to $86 \pm 15 \%$ on day $C ;$ none of these fluctuations were significant $(p>0.1)$.

Percentage of Total Questions Correctly Answered (Fig. 3)

The percentage of total questions correctly answered by the experimental group did not significantly change ( $p>0.1)$ from day A $(70 \pm 18 \%)$ to day $B(81 \pm 8 \%)$. This percentage increased a month later (day C) to $89 \pm 3 \%$. This was marginally significant $(p<0.1)$ 


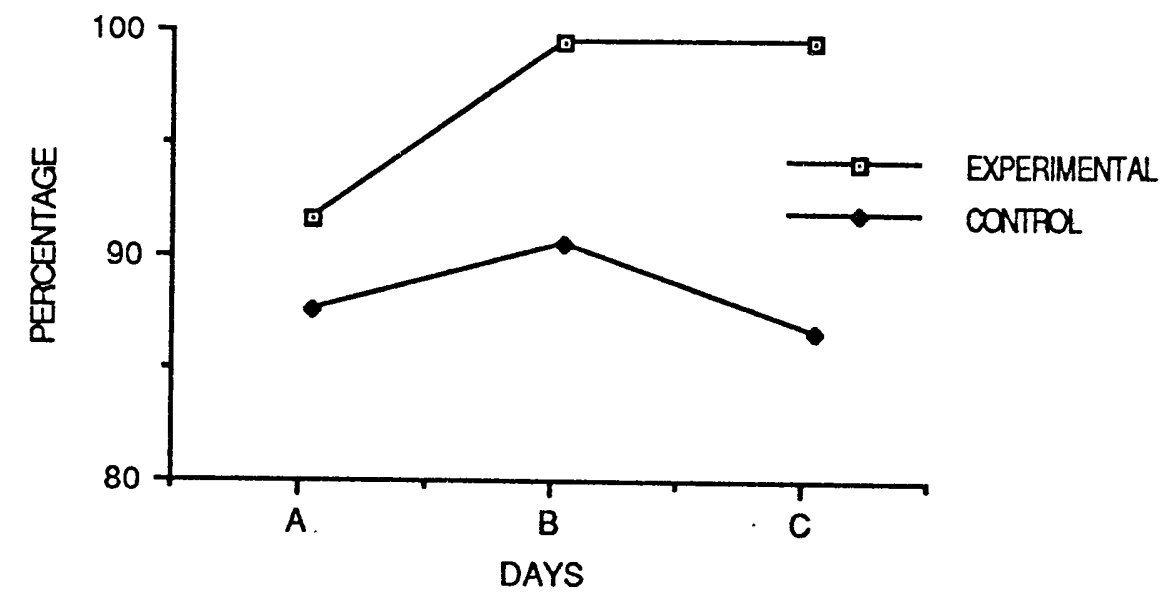

Figure 2. Mean Percentage of Total Questions Answered.

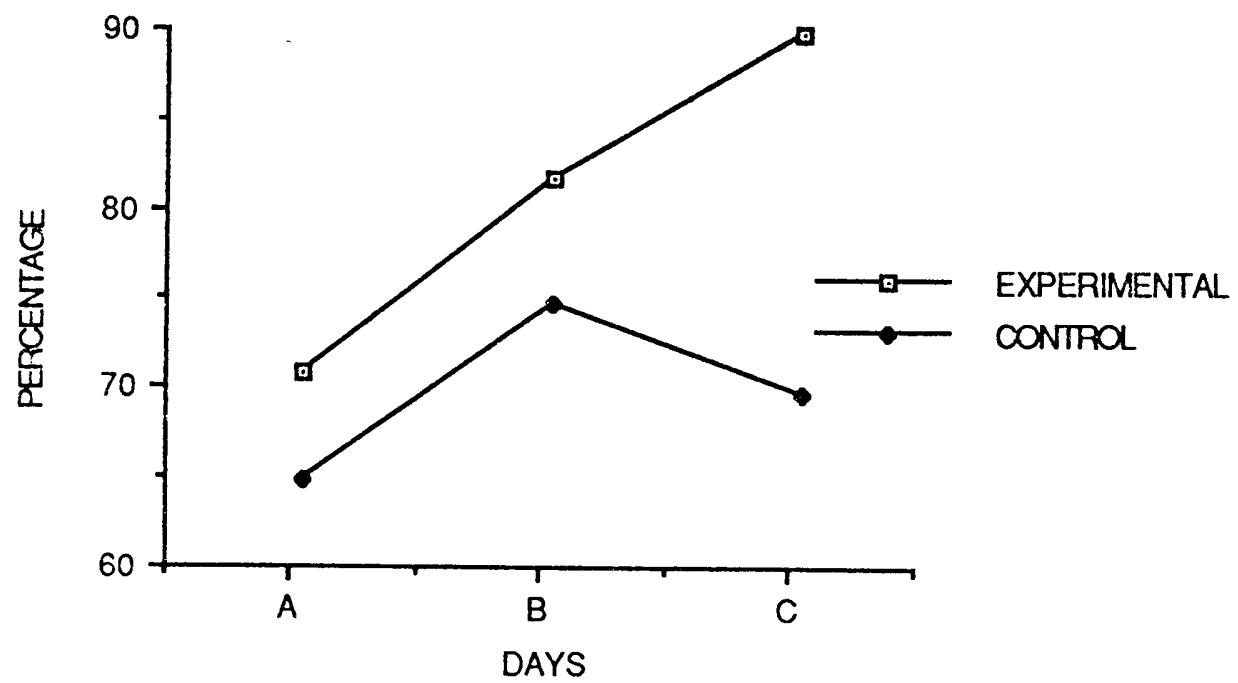

Figure 3. Mean Percentage of Total Questions Correctly Answered. 
The percentage of total questions correctly answered by the control group were $64 \pm 15 \%$ on day $A, 74 \pm 8 \%$ on day $B$ and $69 \pm 13 \%$ on day $C$, which were not statistically different $(p>0.1)$.

Percentage of Answered Questions Correctly Answered (Fig. 4) In the experimental group, the percentage of answered questions answered correctly increased from $76 \pm 14 \%$ on day A and 82 $\pm 8 \%$ on day $B$ to $91 \pm 3 \%$ on day $C$, with the increase from day $B$ to day $c$ being significant $(p<0.06)$. As for the control group, these values were $74 \pm 8 \%, 82 \pm 1 \%$, and $81 \pm 7 \%$ on days $A, B$, and $C$, respectively, showing no significant change.

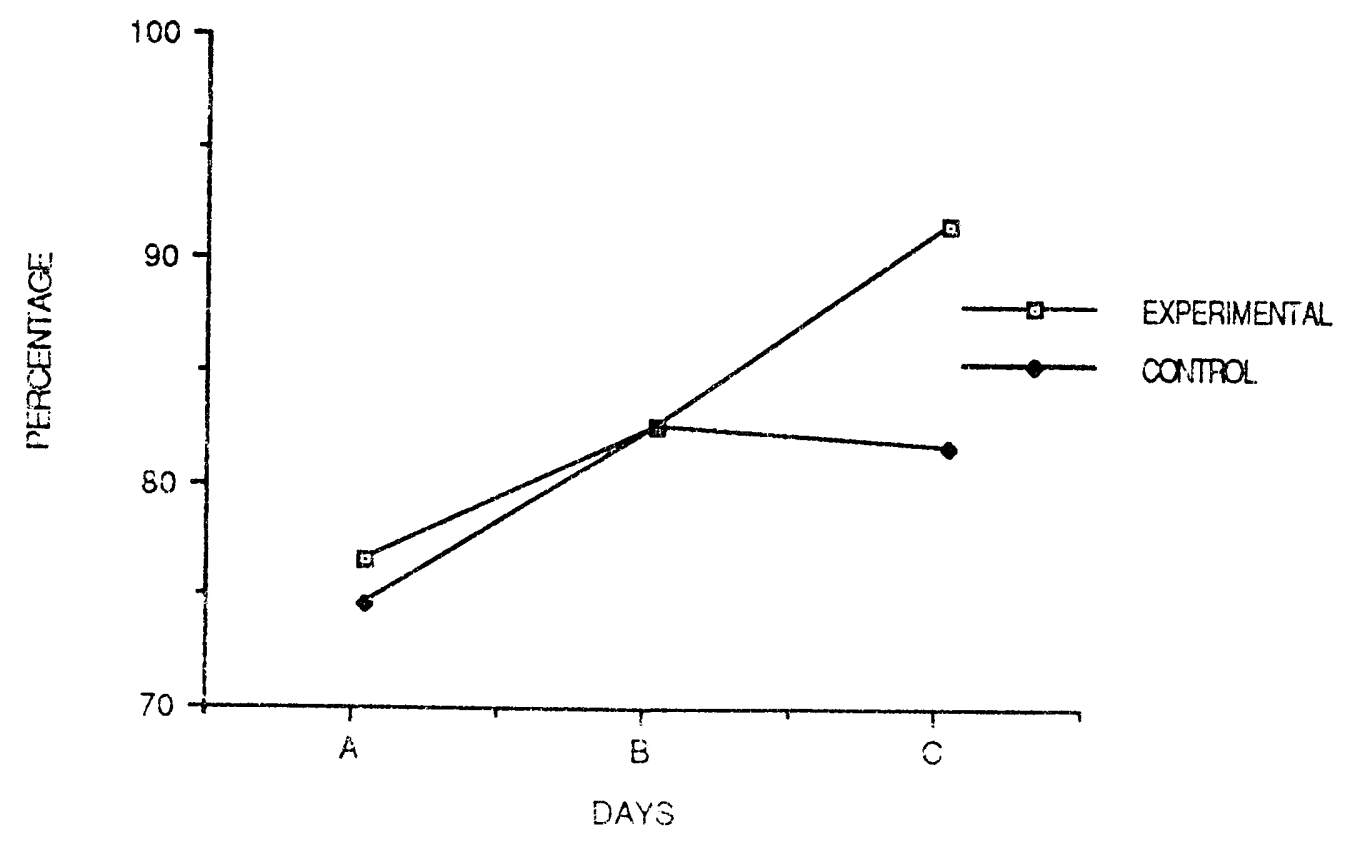

Figure 4. Nean Percentage of Answered questions Correctiy Arsiered. 


\section{Misconceptions Not Corrected with Nutrition Education}

\section{Beliefs Questions}

The most common idea that members of both groups believed, mistakenly, is that some foods will strengthen their immune system $(3 / 4$ subjects in the experimental group; $2 / 3$ answers in control group). In addition, the control group believed that the Dr. Berger's Immune Power Diet might keep them well $(2 / 3)$; and that the macrobiotic diet might keep them healthy $(2 / 3)$.

\section{Practical Questions}

As for the practical aspects of nutrition, most subjects did not know or learn that whole milk provides the same vitamins and minerals as skim milk plus energy (50\% experimental group; $100 \%$ control group). Forty-two percent of the members of the experimental group did not think that rice and beans were a good food combination of vegetable protein or that by limiting the peeling of fruits and vegetables nutrient loss is limited.

Fifty-six percent of the control group did not know that it is recommended to increase the intake of calories and protein; $67 \%$ of them were not aware that they should eat as much as possible when feeling well to compensate for times when they do not feel like eating; and none of them thought that eating so called "junk" foods was OK (100\%). 


\section{Aspects Known by All}

In contrast, all participants knew that starving oneself does not starve the virus. The experimental group were aware that intakes of calories and protein should be increased and that a supplement pill providing about $100 \%$ of the RDA for vitamins and minerals should be taken daily. Members of the experimental group all denied the efficacy of the Dr. Berger's Immune Power Diet and of megadoses of vitamins and minerals in keeping them well. The control group believed that their diet had an influence on their disease; that it could not cure them but that a good nutritional status could enhance the benefits from other therapies.

When it came to practice, the control group knew that limiting the peeling of fruits and vegetables, cooking foods in as little water as possible, and protecting foods from heat, light, and air limits nutrient loss.

\section{Knowledge Acquired}

When examining the answer pattern of each group, it was apparent that they learned specific aspects of nutrition by the end of the study. This was shown as certain questions given the wrong answer on day A were correctly answered by every member of the group on day $c$. These items are the following for the experimental group:

- a diet is not a cure

- they should have at least three meals and two snacks daily 
- if vegetarian, they should worry about their intake of vitamin B12, iron, protein, and energy

- the Maximum Immunity diet will not cure them

- the Macrobiotic diet will not keep them healthy

- it is not worth trying just any diet

- a good nutritional status can enhance the benefits from other therapies

- nutrition influences their disease

- washing foods decreases contamination

- they should have around $8 \mathrm{oz}$. of protein food/day

- they should eat when feeling well to compensate for time when they do not feel like eating

- decreasing the cooking length of time limits nutrients loss

- decreasing storage time limit nutrients loss

- decreasing food exposure to heat, light, or air limits nutrients loss

Similarly, the aspects learned by the control group were the following:

- they should take a daily supplement providing $100 \%$ of ther RDA

- they should have at least three meals and two snacks daily

- the Maximum Immunity diet will not cure them

- washing food will decrease the contamination risks

- they can eat any food

- decreasing cooking length of time limits nutrients loss 
- limiting exposure of food to heat, light, or air limits nutrients loss.

\section{Hypothesis Verification}

The number of participants who thought that any diet was worth being tried (\#12) decreased from $3 / 4$ on day $A$ to $1 / 4$ on day $B$ and $0 / 4$ on day $C$ in the experimental group. In the control group, on day $A, 1 / 3$ answered that it was worth trying any diet and $1 / 3$ did not answer to the question; on day $B 1 / 3$ did not answer to the question; and on day $C, 1 / 3$ thought that any diet was worth being tried.

Nutrient Intake (Tables 2-4)

Pre-Lectures Values: Comparison Between Groups (Table 5)

Two sample t-tests between groups were performed on nutrient intake as analyzed by computrition*. Intakes on day A were similar in both groups for most of the 20 nutrients analyzed. They differed, however, for energy $(p<0.04)$, fat $(p<0.10)$, carbohydrate $(p<0.07)$, cholesterol $(p<0.10)$, sodium $(p<0.04)$, potassium $(p<0.07)$, and thiamin $(p<0.10)$, the experimental group having a significantly greater intake of these nutrients than the control group.

Concerning the percentage of calories provided by alcoholic beverages, the mean was much greater in the control group (12\%) than in the experimental group $(0 \%)$, although not significantly. Post-Lectures Values: Comparison Between Groups (Table 6)

When intakes on day $B$ were compared to those on day $A$ be- 
tween groups, the mean percentage for the experimental group of recommended intake for cholesterol and sodium decreased significantly more than for the control group $(p<0.10)$. Also, the difference between groups in change in percentage of kilocalories provided by protein was significant $(p<0.10)$.

The same tests were performed regarding a change between day $B$ and day $C$. There were no significant change in intake modification between groups for any nutrient except for phosphorus $(p<0.04)$. The control group significantly decreased their intake of phosphorus while the experimental group significantly increased it.

\section{Nutrient Intake Pattern: Comparison within Groups}

Intake did not significantly change from day $A$ to day $B$ in the experimental group for any nutrient except for cholesterol $(p<0.08)$. Their intake of cholesterol was significantly decreased after the fourth nutrition lecture.

Also, the percentage of calories provided by protein decreased on day B (mean $12 \%$ ) as compared to that on day A (mean 15\%). The percentage of calories from protein origin was significantly lower $(\mathrm{p}<0.08)$ after nutrition education than before.

One month following the last nutrition lecture, there were no significant changes in the intake of any nutrient except for phosphorus $(p<0.08)$. The intake of this nutrient was significantly higher on day C (mean $2190 \mathrm{mg} / \mathrm{d}$ ) than on day B (mean $1500 \mathrm{mg} / \mathrm{d}$ ) in the experimental group (Table 3). 


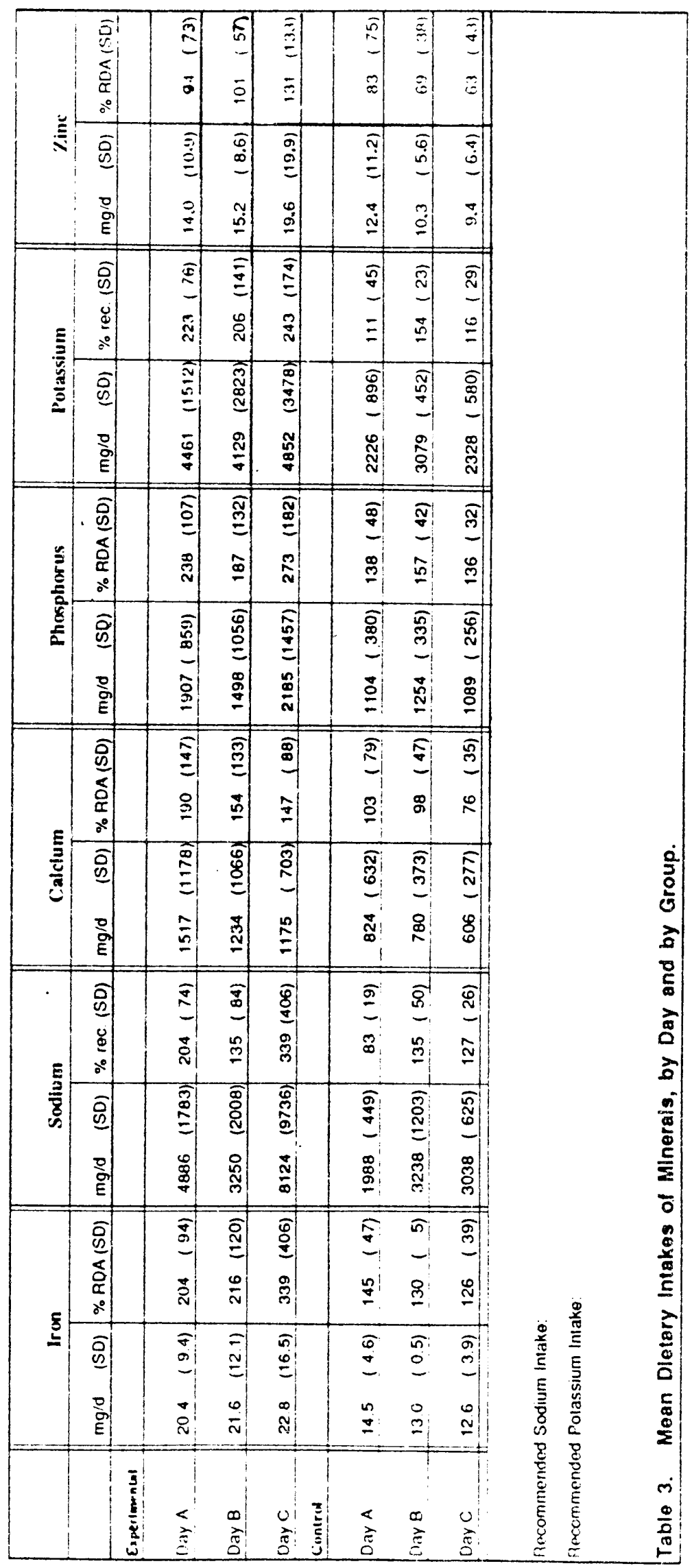




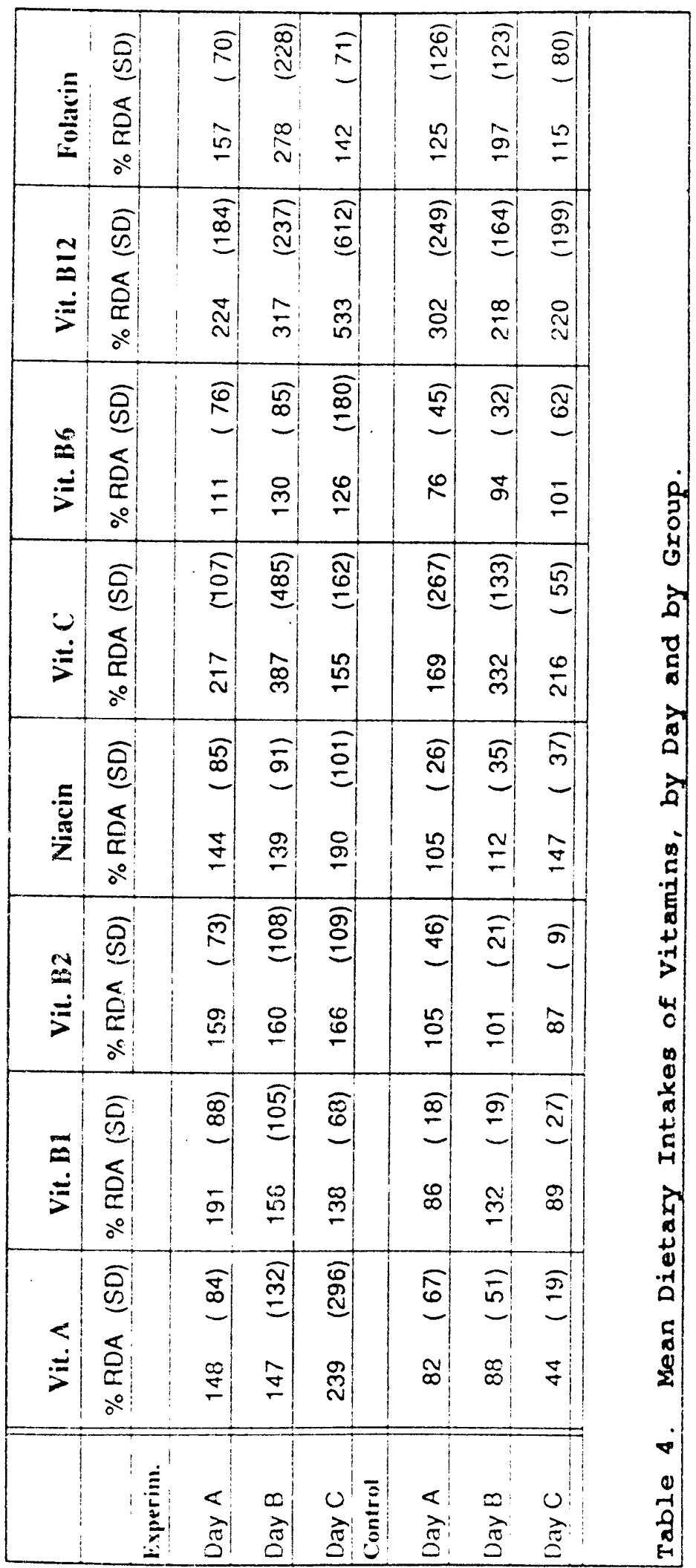


The control group showed a significantly higher intake in phosphorus $(p<0.04)$ and in potassium $(p<0.08)$ on day $B$ than on day A; mean daily intakes increased from $1100 \mathrm{mg}$ to $1250 \mathrm{mg}$ of phosphorus and from $2230 \mathrm{mg}$ to $3080 \mathrm{mg}$ of potasium. As for other nutrients, there were no significant change after four lectures.

A month later, however, dietary intakes of niacin were significantly increased $(p<0.01)$ and dietary intakes of folacin significantly decreased $(p<0.09)$ in this group.

The percentage of calories from carbohydrates was significantly higher on day C (56\%) than on day B $(50 \%)$ or day A $(47 \%)$ $(p<0.1)$. In parallel, the percentage of calories from fat decreased from $37 \%$ on day A to $34 \%$ on day $B$ and $27 \%$ on day $C$, although not significantly.

Nutrient Intake: Comparison with Recommendations (Table 2)

The experimental group's intake of calories and protein did not significantly differ from the recommended intakes for HIVinfected individuals on either day recalled. Mean intakes ranged from $91 \%$ to $116 \%$ of recommendations for energy and from $144 \%$ to $288 \%$ of those for protein.

The control group's intake of calories was significantly lower than recommended for that population on day $A$ and day $B$ $(p<0.08)$. Their intake of protein was significantly higher than recommended on day $c(p<0.06)$. 


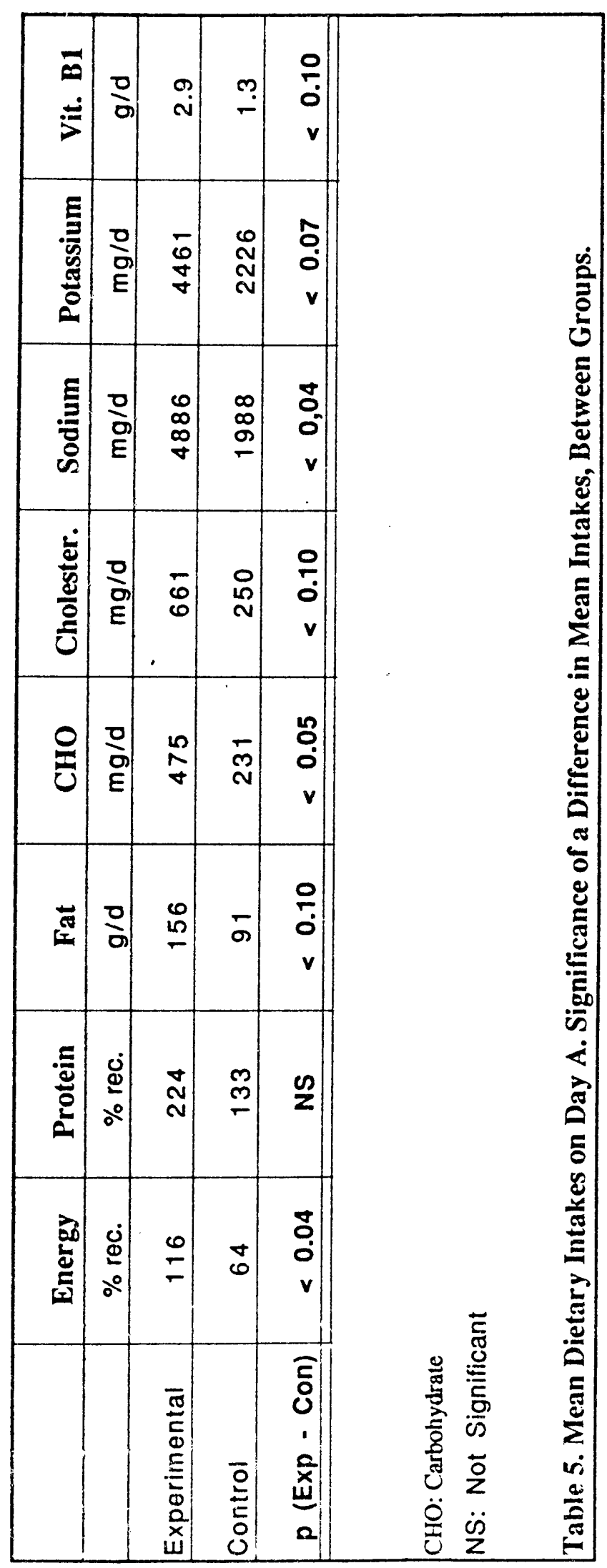




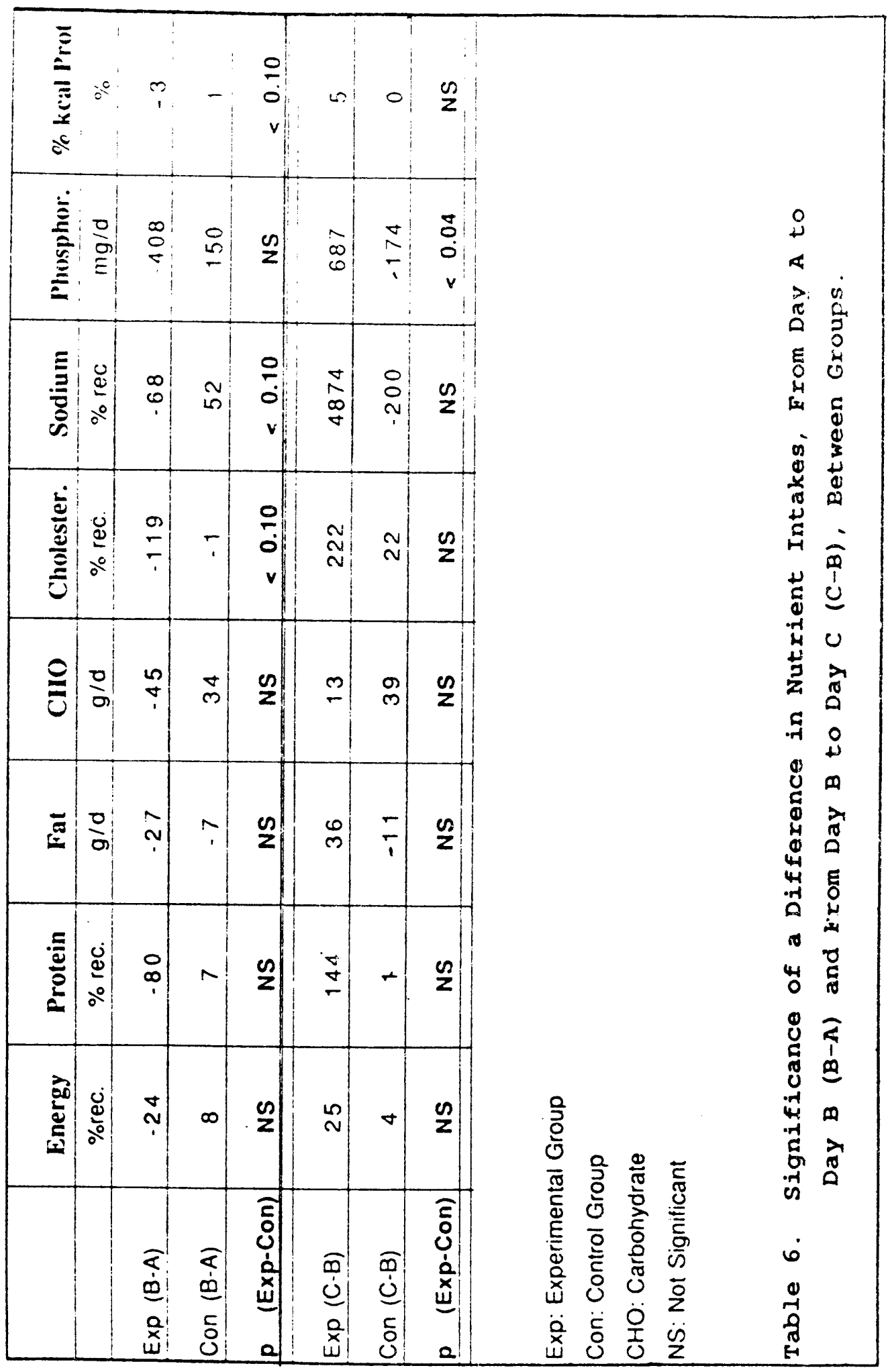




\section{Discussion}

This study demonstrates that nutrition education increases the nutrition knowledge of HIV infected individuals making them less vulnerable to nutrition quackery. As hypothesized, members of the experimental group significantly increased their scores on the nutritional knowledge questionnaire after education and their willingness to try any diet was totally eliminated.

\section{Nutrition knowledge}

All members of the experimental group showed an increase in their confidence level in knowledge as the number of questions answered steadily increased throughout the study. Even on day $\mathrm{C}$, when subjects were expected to have forgotten some of the material presented, they answered more questions than on day $B$, although the difference was not significant. In contrast, only $1 / 3$ of the control group increased the number of questions answered. This number decreased for $1 / 3$ of the members. It should be noted that all participants' knowledge level were higher than expected. Apparently, questions were not very difficult for them. This explains the high scores obtained on day A. Consequently, improvements were slight and difficult to show statistically on such a small group.

The percentage of total questions correctly answered increased in the experimental group. This increase possibly reveals the gain of knowledge from day $A$ to day $C$, as a result of 
the nutrition lectures. Statistically, this increase was marginally significant. In the control group, this percentage varied also, but not in a consistent manner. Therefore, no conclusion of an increase in knowledge could be reached.

A significant increase in the percentage of answered questions correctly answered could be shown, strongly indicating the acquiring and maintaining of knowledge in the experimental group. In contrast, there were no significant nor consistent change in the control group. This most encouraging result shows that members listened to and retained the information presented during the lectures. In addition, they could answer the questions correctly after a month without contact with the lecturer. This suggests that either the knowledge was acquired on the long-term span, that they kept informed on the topics presented, or that they reviewed some of the written material handed before meeting on day $c$. It should be noted, however, that the handouts hardly covered all topics discussed in the questionnaire. In addition, it was rare that a question correctly answered on days $A$ or $B$ were given the wrong answer or even left unanswered on day $c$. This confirms the suggestion that knowledge was acquired solidly through the lectures and/or reinforced by self-gathered information.

\section{Population size}

The size of the groups is of importance in interpreting the results. Small groups $(n<30)$ as represented in this study usual- 
ly present a wider variability than larger groups $(n>30)$. Therefore, it is difficult to interpret variations in results over a two-month-period. Also, this questionnaire was not previously validated; therefore, results can not be compared to a "normal" value. Results can not be compared to other studies as none were found in the literature.

However, it should be pointed out that results from the experimental group were consistently positive even if only marginally significant; a remark that is not true of results from the control group. In addition, standard deviations got smaller as the study progressed in the experimental group for all knowledge values; this did not occur in the control group. It seems that results from a larger sample would have allowed for a stronger indication of a learning process.

Moreover, the interest level of the experimental group as subjectively measured by the lecturer shows an increase in knowledge or at least an increase in the willingness to be exposed to information and to learn. It is anticipated that a longer exposure to nutrition education would have resulted in more significant results.

\section{Nutrient Intakes}

Data from 24-hr. recalls revealed that energy and protein intakes in the experimental group did not significantly differ from the recommended intakes for HIV-infected individuals on all three days. They were mostly over $100 \%$ of recommendations. In 
contrast, the mean intake of energy in the control group was lower than recommended on days $A$ and $B ;$ the mean intake of protein was significantly higher than recommended on day $C$. This latter fact is probably an isolated event rather than the result of an actual change in behavior. Overall, the experimental group started (day A) with a more nutritionally sound intake pattern than the control group. This observation, added to the fact that they volunteered for the lectures, might indicate a higher level of interest and/or motivation in nutrition from the experimental group. Many mean nutrient intakes between groups differed on day A. Therefore, changes in nutrient intakes from day $A$ to day $B$ and from day $B$ to day $C$ were compared between the two groups to eliminate pre-lectures differences.

\section{Calorie distribution}

There was a significant decrease in percentage of calories provided by protein in the experimental group, although percentages of calories were not discussed in the lectures. Recommended protein intakes were expressed in terms of grams of protein per pound of body weight. Nevertheless, the first and second lectures stressed out the point that protein needs were increased in HIV-infected individuals and that, consequently, intake of foods rich in protein should be increased. Whether this aspect was misinterpreted or the decreased intake was a coincidence linked to a single day being recalled is not clear. 


\section{Cholesterol, Phosphorus, and Potassium}

Interestingly, there were significant changes in intakes of cholesterol, niacin, phosphorus, and potassium in the two groups, although none of these nutrients were discussed as such during the lectures. Therefore, it seems reasonable to assume that these changes were not linked to nutrition education.

\section{Diet supplementation}

One of the hypotheses postulated that the number of subjects taking a supplement pill of vitamins and minerals providing approximately $100 \%$ of the RDA daily would increase in the experimental group and remain unchanged in the control group. This hypothesis could not be verified as all participants were taking such a supplement on day $A$.

\section{vulnerability to Nutrition Fraud}

Results suggest that once participants received nutrition education, they were less inclined to try any diet as a treatment for their condition. By day $c$, none of the members of the experimental group were willing to try or recognized the value of fad or unproven therapeutic diet, as opposed to $3 / 4$ of the members on day A. This observation validates the positive impact of education in an HIV-infected population, as it reduces the probability for this population to try a diet that will give them a false hope, will not improve their condition, and might even jeopardize their

state

of

health. 
Decreasing the vulnerability of this population to fraudulent diet therapies is important. It was estimated than Americans have spent $\$ 1$ billion on fraudulent AIDS therapies in 1989, including nutritional therapies (101, 102). People with chronic diseases are vulnerable to fraud (103). Many books and newsletters promote possibly harmful nutritional regimens (104-112). Non-scientific techniques include supplements to the usual diet (113-116) or the elimination of certain types of foods $(65,20)$; others advocate a radical change of the diet (20); and, more dangerously, other request the total reliance on the regimen that totally substitutes for responsible, controlled medical intervention (117-120). In general, the danger in following such diets is that strict regimens proposed usually result in nutritional deficiencies or overdoses or go against the recommendations for increased needs of PWA jeopardizing their nutritional status.

Knowing that a placebo effect can provide mental and, to some extent, physical improvement in chronic illness and being aware of differing culturally-linked nutritional beliefs, the American Public Health Association (APHA) encourages the development of educational programs for PWA that include therapeutic nutrition intervention based on sound scientific principles while respecting individuals cultural beliefs and convictions as long as not harmful (75). This study supports the proposal of the APHA by showing that just four nutrition lectures can have a considerable impact on the HIV-infected individual by decreasing 
their willingness to try any diet and making them less vulnerable to quackery. 


\section{Chapter Five:}

\section{Conclusions and Recommendations}

This study investigated the impact of short-term (one month) nutrition education on the knowledge level and intake of individuals infected with the human immunodeficiency virus. The goal was to determine whether an increase in knowledge would lead to a spontaneous improvement of intake. Also, it was sought whether subjects would be less vulnerable to quackery once educated. Results indicated that nutrition education considerably increased the nutrition knowledge level of HIV-infected individuals. Participants in the experimental group significantly improved their scores on the knowledge questionnaire after four nutrition lectures. Scores even increased further a month after completion of the education program. It could not be shown, however, that the acquiring of knowledge leads to a significant change in food intake. This may be due to the small size of the populations and the dietary survey methods involved in this study. Also, individual counseling is probably needed for a behavior modification in this population as well as in any population. Nevertheless, results strongly demonstrate that education lessens the probability that HIV-infected persons would follow a fad, dangerous diet after nutrition education. A result that, in itself, validates the necessity of education for all HIV-infected individuals as soon as diagnosed positive for HIV. 
As the groups studied were small, it is recommended that similar studies be undertaken examining a larger population so that results can be extrapolated to the HIV-infected population. Groups could be formed according to stages of the disease, age, and/or route of contamination. This would allow for a program tailored to specific needs. Also, four lectures were found to be insufficient to cover all aspects of nutritional care in as much details as desired by participants. It would be recommended to extend the number of lectures to six or eight sessions of at least 30 minutes. Finally, the "rest" period (between day B and day c) could be prolonged, giving more weight to the results. The results of this study were encouraging enough to strongly recommend that further research on nutrition education of HIV-infected individuals be undertaken. 


\section{REFERENCES}

1 Hebert, J.R., Barone, J.: On the possible relationship between AIDS and nutrition. Med Hypotheses 27(1):51, 1988 .

2. Crocker, K.S.: AIDS-related GI dysfunction: Rationale for nutrition support. Crit Care Nurse $8(3): 43,1988$.

3. Clinical Nutrition Cases. Severe malnutrition in a young man with AIDS. Nutr Rev $48(3), 1988$.

4. Colman, N., Grossman, F.: Nutritional factors in epidemic Kaposi's sarcoma. Semin Oncol 14(2 Suppl.3):54, 1987.

5. Dworkin, B., Wormser, G.P.: Gastrointestinal manifestation of the acquired immunodeficiency syndrome: A review of 22 cases. Am J Gastroenterol 80:774, 1985.

6. Kotler, D.P.: Enteropathy associated with the acquired immunodeficiency syndrome. Ann Int Med 101:421, 1984.

7. Kotler, D.P.: Intestinal and hepatic manifestations of AIDS. Adv Intern Med 34:43, 1989.

8. Strauss, J., Abitbol, C., Zilleruelo, G., Scott, G., Paredes, A., Malaga, S., Montane, B., Mitchell, C., Parks, W., Pardo, V.: Renal disease in children with the acquired immunodeficiency syndrome. $\mathrm{N}$ Engl J Med 321:625, 1989.

9. Schorr, J.B., Berkowitz, A., Cumming, P.D., Katz, A.J., Sandler, S.G.: Prevalence of HTLV-III antibody in American blood donors. N Engl J med 313:384, 1985 .

10. Human T-lymphotropic virus type III/lymphadenopathy. Associated virus antibody prevalence in Us military recruit applicants. MMWR 35(26):421, 1986.

11. Cunningham-Rundles, S.: Effects of nutritional status on immunological function. Am J Clin Nutr 35:1202, 1982 .

12. Jain, V.K., Chandra, R.K: Does nutrition deficiency predispose to acquired immunodeficiency syndrome? Nutr Res 4:537, 1984 .

13. Shen, P.F.L.: Medical Hypothesis: Multiple infections and protein-calorie malnutrition as key cofactors in the pathogenesis of full-blown acquired immunodeficiency syndrome (AIDS) - CAPA86 Conference Proceedings, 1986. 
14. Bartley, K.C.: Dietetic Practitioner Skills: Nutrition Education, Counseling and Business Management. New York: Mac Millan Publishing Company, 1987.

15. Chelbowski, R.T.: Significance of altered nutritional status in acquired immune deficiency syndrome (AIDS). Nutr Cancer $7: 85,1985$.

16. ADA Reports. Position of the American Dietetic Association: Nutrition intervention in the treatment of human immunodeficiency virus infection. J Am Diet Assoc 89:839, 1989.

17. Hickson, J.F., Knudson, P.: Optimal eating. Nutritional guidelines for PWAs.AIDS Patient Care December:28, 1988.

18. Gray, R.H.: Similarities between AIDS and PCM. Am J Public Health $73: 1332,1983$.

19. Dwyer, J.T., Bye, R.L., Holt, P.L., Lauze, S.R.: Unproven nutrition therapies for AIDS: what is the evidence? Nutrition Today 23:25, 1988 .

20. Collins, C.L.: Nutrition care in AIDS. Diet Currents $15(3): 11,1988$.

21. Beach, R.S.: Altered folate metabolism in early HIV infection. J Am Med Assoc 259:519, 1988.

22. Beach, R.S., Laura, P.F.: Nutrition and the acquired immunodeficiency syndrome. Ann Intern Med 99:565, 1983.

23. Domaldo, T.L., Natividad, L.S.: Nutritional management of patient with AIDS and cytosporidium infection. Nutr supp ser $6(4): 30,1986$.

24. Resler, S.S.: Nutrition care of AIDS patients. J Am Diet Assoc $88: 828,1988$.

25. Budd, C.B.: Nutritional care of patients with pneumocystis carinii pneumonia. Nutr Supp Ser 2(12):12, 1982.

26. Fultz, P.: The biology of human immunodeficency viruses. In: Kaslow, R.A., Francis, D.P., eds.: The Epidemiology of AIDS. Expression, Occurence, and Control of Human Immunodeficiency Virus Type 1 Infection. New York: Oxford University Press, 1989.

27. Lewis, J.E.: Biology of HIV infection. In: Hopp, J.W., Rogers, E.A., eds.: AIDS and the Allies Health Professions. Philadelphia: F.A. Davis Companie, 1989. 
28. Curran, J.W., Jaffe, H.W., Hardy, A.M., Morgan, W.M., Selik, R.M., Dondero, T.J.: Epidemiology of HIV infection and AIDS in the United States. Science 239:610, 1988.

29. Statistics from the World Health organization and the Centers for Disease Control. AIDS 4:825, 1990.

30. Heyward, W.L., Curran, J.W.: The epidemiology of AIDS in the US. Sci Am 259(4):72, 1988 .

31. Centers for Disease Control. Revision of the Centers for Disease Control surveillance definition for acquired immunodeficiency syndrome. MMWR 36(1S):3S, 1987.

32. Gallo, R.C., Montagnier, L.: AIDS in 1988. Sci Am 259:41, 1988

33. Elder, H.A.: What the HIV causes: clinical manifestations and diagnoses. In: Hopp, J.W., Rogers, E.A., eds.: AIDS and the Allies Health Professions. Philadelphia: F.A. Davis Companie, 1989 .

34. Rogers, P., Masur, H.: The immune system: clinical manifestations. In: Hopp, J.W., Rogers, E.A., eds.: AIDS and the Allies Health Professions. Philadelphia: F.A. Davis Companie, 1989.

35. McCaffrey, E.A.: Meeting nutritional needs. Stimulating appetite and maximizing caloric intake. AIDS Patient Care september:28-31, 1987 .

36. Sato, S.J., Mirtallo, J.M.: Nutritional support for the AIDS patient. US Pharmacist, dec 1987.

37. Detmer, W.M., Lu, F.G.: Neuropsychiatric complications of AIDS: A literature review. Int J Psychiatry Med 16:21, 19861987 .

38. Kotler, D.P., Wang, J., Pierson, R.N.: Body composition studies in patients with the acquired immunodeficiency syndrome. Am J Clin Nutr 42:1255, 1985.

39. Gelb, A., Miller, S.: AIDS and gastroenteroly. Am J Gastroenterol 81:619, 1986 .

40. Bluhm, C.S., Bickerstaff, C.A., Holt, S.: Refractory esophageal candidiasis in acquired immune deficiency syndrome (AIDS), letter. Am J Gastroenterol 85(4):479, 1990. 
41. Budhraja, M., Levendoglu, H., Kocka, F., Mangkornkanok, M., Sherer, R.: Duodenal mucosal $T$ cell subpopulation and bacterial cultures in acquired immune deficiency syndrome. Am J Gastroenterol $82(5): 427,1987$.

42. Parkin, D.M., McLelland, d.B., o'Moore, r.R.: Intestinal bacterial flora and bile salt studies in hypogammaglobulinelia.Gut 13:182, 1972 .

43. Smith, P.D., Lane, C., Gill, V.J., Manischewitz, J.F., Quinnan, G.V., Fauci, A.S., Masur, H.: Intestinal infections in patients with the acquired immunodeficiency syndrome (AIDS). Etiology and response to therapy. Annals of Internal Medicine $108: 328-33$, 1988 .

44. Philipps, S.C., Mildvan, D., William, D.C., Gelb, A.M., white, M.C.: Sexual transmission of enteric protozoa and helminths in a veneral-disease-clinic population. $N$ Engl J Med $305: 603$, 1981 .

45. Quinn, T.C.: Gastrointestinal manifestations of AIDS. Pract Gastroenterol 9:23, 1985 .

46. Quinn, T.C., Stamm, W.E., Goodell, S.E.: The polymicrobial origin of intestinal infections in homosexual men. $\mathrm{N}$ Engl $\mathrm{J}$ Med $309: 576,1983$.

47. Owen, W.F.Jr.: Sexually transmitted diseases and traumatic problems in homosexual men. Ann Int Med 92:805, 1980

48. Baker, R.W., Peppercorn, M.A.: Gastrointestinal ailments of homosexual men. Medicine 61:390, 1982 .

49. Stahl-Bayliss, C.M., Kalman, C.M., Laskin, O.L.: Pentamidine-induced hypoglycemia in patients with the acquired immune deficiency syndrome. Clin Pharmacol Ther 39:271, 1986.

50. Dworkin, B.M., stahl, R.E., Giardina, M.A., Wormser, G.P., Weiss, L., Jankowski, R., Rosenthal, W.S.: The Iiver in acxquired immune deficiency syndrome: emphasis on patients with intravenous drug abuse. The American Journal of Gastroenterology 82(3):2316,1987 .

51. Goedert J.J., Blattner, W.A.: The epidemiology of AIDS and related conditions. In: DeVita V.T. Jr., Hellman, S., Rosenberg, S.A. eds. AIDS: etiology, diagnosis, treatment, and prevention. Philadelphia: J.B. Lippincott, 1985. 
52. Rao, T.K.S., Fillipone, E.J., Nicastri, A.D.: Associated focal and segmental glomerulosclerosis in the acquired immunodeficiency syndrome. N Engl J Med 310:669, 1984.

53. Pardo, V., Aldana, M., Colton, R.M, Fischl, M.A., Jaffe, D., Moskowitch, L., Hensley, G.T., Bourgoignie, J.J.: Glomerular lesions in acquired immunodeficiency syndrome. Ann Int Med $101: 429$, 1984 .

54. Beisel, W.R., Edelman, R., Nauss, K., Suskind, R.M.: Single-nutrient effects on immunologic functions. J Am Med Assoc 245:53, 1981 .

55. Chandra, R.K.: Nutrition, immunity, and infection: present knowledge and future directions. Lancet 1:688, 1983.

56. Pierson, R., Wang, J., Thornton, J., Van Itallie, T., Colt, E.: Body potassium by four-pi K counting: an anthropometric correction. Am J Physiol 246:234, 1984.

57. Ortiz, R., Betancourt, M.: Cell proliferation in bone marrow cells of severely malnourished animals. J Nutr 114:472, 1984.

58. Kotler, D.P., Tierney, A.R., Wang, J., Pierson, R.N.: Magnitude of body-cell-mass depletion and the timing of death from wasting in AIDS. Am J Clin Nutr 50:444, 1989.

59. Sirisinha, S., Suskind, R.M., Edelman, R.: Secretory and serum IgA in children with protein-caloric malnutrition. Pediatrics $55: 166$, 1975 .

60. Keusch, C.T., Orrutia, J.J., Fernandez, R., Guerrero, O., Castenada, G.: Humoral and cellular aspects of intracellular bacterial killing in Guatemala children with protein-calorie malnutrition. In: Sudskind R.M., ed. Malnutrition and the immune response. New York:Raven Press, 1977.

61. Saxena, Q.B., Saxena, R.K., Adler, W.H.: Effect of protein calorie malnutrition on levels of natural and inducible cytotoxic activities in mouse spleen cells. Immunology 51:727, 1984.

62. Ongsakul, M., Sirisinhas, S., Lamb, A.J.: Impaired blood clearance of bacteria and phagocytic activity in vitamin Adeficient rats. Proc Soc Exp Biol Med 178:204, 1985.

63. Smith, S.M.: Contrasting impairements in IgM and IgG responses of vitamin A-deficient mice. proc Natl Acad SCi USA $84: 5878,1987$. 
64. Pike, J.T.: Alternative nutritional therapies. Where is the evidence? AIDS Patient Care February:31, 1988.

65. Henochowicz, S., Hoth, D.: Unproven agents in the treatment of human immunodeficiency virus (HIV) infection. AIDS Updates $1: 1,1988$.

66. Quinones, A., Lifshitz, A., Aguirre-Garcia, J., HalabeCherem, J., Laredo, F., Vasquez-Saavedra, J.A.: [Treatment of enteropathy in AIDS with a gluten-free diet. Preliminary communication.] Tratamiento de la enteropatia del SIDA con una dieta sin gluten. Communicacion preliminar. Rev Invest Clin 4:223, 1989.

67. Mandau, C., Palac, B.: Use of a fiber-containing enteral formulation in an AIDS patient. Nutr Clin Pract 4:136, 1989.

68. Office of Compliance (HFN 304), Centers for Drugs and Biologies, DHHS: Fraudulent AIDS products. Health Fraud Bulletin \#10, July 15, 1987.

69. The Task Force on Nutrition Support in AIDS. Guidelines for nutrition support in AIDS. AIDS Patient Care aug:32, 1989.

70. Collins, C.L.: AIDS and nutritional care. RD 7(3):6, 1987.

71. Task Force on Nutrition support in AIDS. Guidelines for nutrition support in AIDS. Nutrition 5:39, 1989.

72. Freed, J.S., Reiner, M.A.: Nutrition, survival, and AIDS, letter. Am J Gastroenterol 85(4):476, 1990 .

73. Shamberger, R.C., Brennean, M.F., Goodgame, T.: A prospective, randomized study of adjuvant parenteral nutrition in the treatment of sarcomas: Results of metabolic and survival studies. Surgery $96: 1,1984$.

74. Samuels, M.L., Selig, D.E., Ogden, S.: Hyperalimentation and chemotherapy for stage III testicular cancer: A randomized study. Cancer Treat Rep 65:615, 1981.

75. The American Public Health Association: Nutrition fraud and AIDS. Am J Public Health 79:358, 1989.

76. Del Tredici, A.M., Block Joy, A., Omelich, C.L., Laughlin, S.G.: Evaluation study of the California Expanded Food and Nutrition Education Program: 24-hour food recall data. J Am Diet Assoc 88: 185, 1988 .

77. Harris, P.T.: Effects of foods and nutrition education on food practices of low income families in four Mississipi coun- 
ties, Summer, 1966. Agricultural Experimental station, Home Economics Series No.3, State College, MS, 1967.

78. Amstutz, M.K., Dixon, D.L.: Dietary changes resulting from the Expanded Food and Nutrition Education Program. J Nutr Educ $18: 55,1986$.

79. Boeckner, L.S., Kohn, H., Rockwell, S.K.: A risk-reduction nutrition course for adults. J Am Diet Assoc 90:260, 1990.

80. William, S.R.: Nutrition and Diet Therapy, Sixth Edition. St Louis: Times Mirror/ Mosby College Publishing, 1989.

81. Beaton, G.H.: What do we think we are estimating? In: Proceedings of the symposium on dietary data collection, analysis, and significance. Amherst: University of Massachusetts Research Bulletin 675:36, 1982 .

82. Beaton, G.H., Milner, J., McGuire V., Feather, T.., Little, J.A.: Source of variance in 24-hour dietary recall data: Implications for nutrition study design and interpretation. Carbohydrates sources, vitamins and minerals. Am J Clin Nutr 37:986, 1983 .

83. Young, C.M., Hagen, G.C., Tucker, R.E., Foster, W.D.: A comparison of dietary study methods. II. Dietary history vs. seven-day record vs. 24-hr. recall. J Am Diet Assoc 28:218, 1952 .

84. Linusson,E.E.I., Sanjur, D., Erikson, E.C.: Validiting the 24-hour recall method as a dietary survey tool. Arch Latinoam Nutr 24:277, 1974 .

85. Greger, J.L., Etnyre, G.M.: Validity of the 24-hour dietary recall by adolescent females. Am J Public Health 68:70, 1978.

86. Gersovitz, M., Madden, J.P., Smiciklas-Wright, H.: Validity of the 24-hour dietary recall and seven-day record for group comparisons. J Am Diet Assoc 73:48, 1978 .

87. Block, G., Dresser, C.M., Hartman, A.M., Carroll, M.D.: Nutrient sources in the American diet: Quantitative data from the NHANES II survey: Vitamins and minerals. Am J Epidemiol 122:13, 1985.

88. Karvetti, R.L., Knuts, L.R.: Validity of the 24-hour dietary recal1. J Am Diet Assoc 85:1437, 1985.

89. Geresovitz, M., Madden, J.P., Smiciklas-Wright, H.: Validity of the 24-hr dietary recall and seven-day record for group com- 
parisons. J Am Diet Assoc 73:48, 1978 .

90. Madden, J.P., Goodman, S.J., Guthrie, H.A.: Validity of the 24-hr. recall. J AM Diet Assoc 68:143, 1976.

91 Karkeck, J.M.: Improving the use of dietary survey methodology. J Am Diet Assoc 87:869, 1987.

92 Decker, M.D., Booth, A.L., Dewey, M.J., Fricker, R.S., Hutcheson, R.H., Schaffner, W.:' Validity of food consumptión histories in a foodborne outbreak investigation. Am J Epidemiol $124: 859$, 1986 .

93. Guthrie, H.A.: Selection and quantification of typical food portions by young adults. J Am Diet AssoC 84:1440, 1984 . 
94. Mann, J.: A prospective study of response errors on food history questionnaires: Implications for food borne outbreak investigation. Am J Public Health 71:1362, 1981.

95. Block, G., Hartman, A.M., Dresser, C.M., Carroll, M.D., Gannon, J., Gardner, L.: A data based approach to diet questionnaire design and testing. Am J Epidemiol 124:453, 1986.

96. Balogh, M. Kahn, H.A., Medalie, J.H.: Random repeat 24-hr. dietary recall. AM J Clin Nutr 24:304, 1971.

97. Hyman, R.T.: Perspective on the Choice of Method. In: Hyman, R.T. ed.: Ways of Teaching. Philadelphia: Lippicott Company, 1970 .

98. Levin, T., Long, R.: Effective Instruction. Alexandria: ASco, 1981 .

99. Hyman, R.T.: The Discussion Method. In: Hyman, R.T. ed.: Ways of Teaching. Philadelphia: Lippicott Company, 1970.

100. National Research Council (U.S.), Subcommittee on the Tenth Edition of the RDAs: Recommended Dietary Allowances, 10th edition. Washington: National Academy Press, 1989.

101. AIDS News: important nutritional facts for patients. Medical Aspects of Human Sexuality. June:134, 1987.

102. Consumer Product safety Network, Vol 5, winter, 1987-88.

103. Young, F.: Allies in the war against health frau. FDA Consumer, March, 1988.

104. Loren, K.: The report on Germanium. Has The cure for Cancer and AIDS Finally Arrived? Glendale: Life Extension Educational Service, 1987.

105. Culbert, M.: AIDS Terror Truth Triumph. Chula Vista: Robert W. Bradford Foundation, 1986.

106. Gregory, S.: Conquering AIDS Now With Natural Treatment. A Non-Drug Approach. Santa Monica: Tree of Life Publication, 1986.

107. Wigmore, A.: Overcoming AIDS and other Incurable Diseases. Boston: Ann Wigmore Foundation, 1986.

108. Serinus, J.: Psychoimmunity and the Healing Process. to Immunity and AIDS. Berkeley: Celestial Arts, 1986. 
109. Badgley, L.: Healing AIDS Naturally. California: Human Energy Press, 1988 .

110. Healing AIDS. San Francisco, 1987.

111. Murray, F.: Lecithin formulas show potential in treating AIDS. Better Nutrition March, 1988.

112. Murray, F.: Vitamin C: A clue for AIDS. Better Nutrition September, 1987.

113. Pauling, L., Cameron, E.: Statement on the treatment of AIDS. Presented to the President's Commission on the Acquired Immune Deficiency Syndrome, Washington, D.C., September 8, 1987.

114. "AL-721 - An overview". In: Gingell, M.D., Barry ed. Treatment Issues 2(1):4-8, Gay Men's Health Crisis, Inc., February 8,1988 .

115. Gavin, S.: AL-721 substitute (home formula). In: Gallen, M., ed.: Surviving and Thriving with AIDS: Hints for the Newly Diagnosed, p.57, People with AIDS Coalition, Inc., New York, NY, 1987.

116. Dextran Sulfate. Project Inform Fact Sheet, Project Inform, San Francisco, CA.

117. McAllister, C.: Renal failure secondary to massive infusion of vitamin C. JAMA 252:1984, 1984.

118. Sistili, M.: Possible adverse health effects of vitamin C and ascorbic acid. Seminars oncol 10:299, 1983.

119. Llaurado, J.: The sage of BHT and BHA in life extension myths. J Am Coll Nutr 4:481, 1985.

120. Wollingscroft, J.: Disease A Month 29:2, 1983. 
HOW TO COMPLETE THE 24 HOUR RECALL

1) Time: write down the approximate time of the day when foods are eaten. Include meals and all snacks.

2) Food description describe the preparation method if known (fried, baked, toasted, whole wheat, with or without skin, canned, frozen, boiled ...). Include seasonings (mustard, mayonnaise, ketchup, $\mathrm{BBQ}$ sauce, salt, tabasco...).

3) Amount: be as specific as possible. Use any measure unit (cup, grams, ounces, fluid ounces, full plate, half full plate, glass, small, large, serving, teaspoon, tablespoon,...). Use amounts actually eaten, DO NOT INCLUDE FOOD LEFT ON PLATE. 


\section{HOUR RECALL}

NAME OR CODE

AGE

HEIGHT

WEIGHT

SEX

DATE

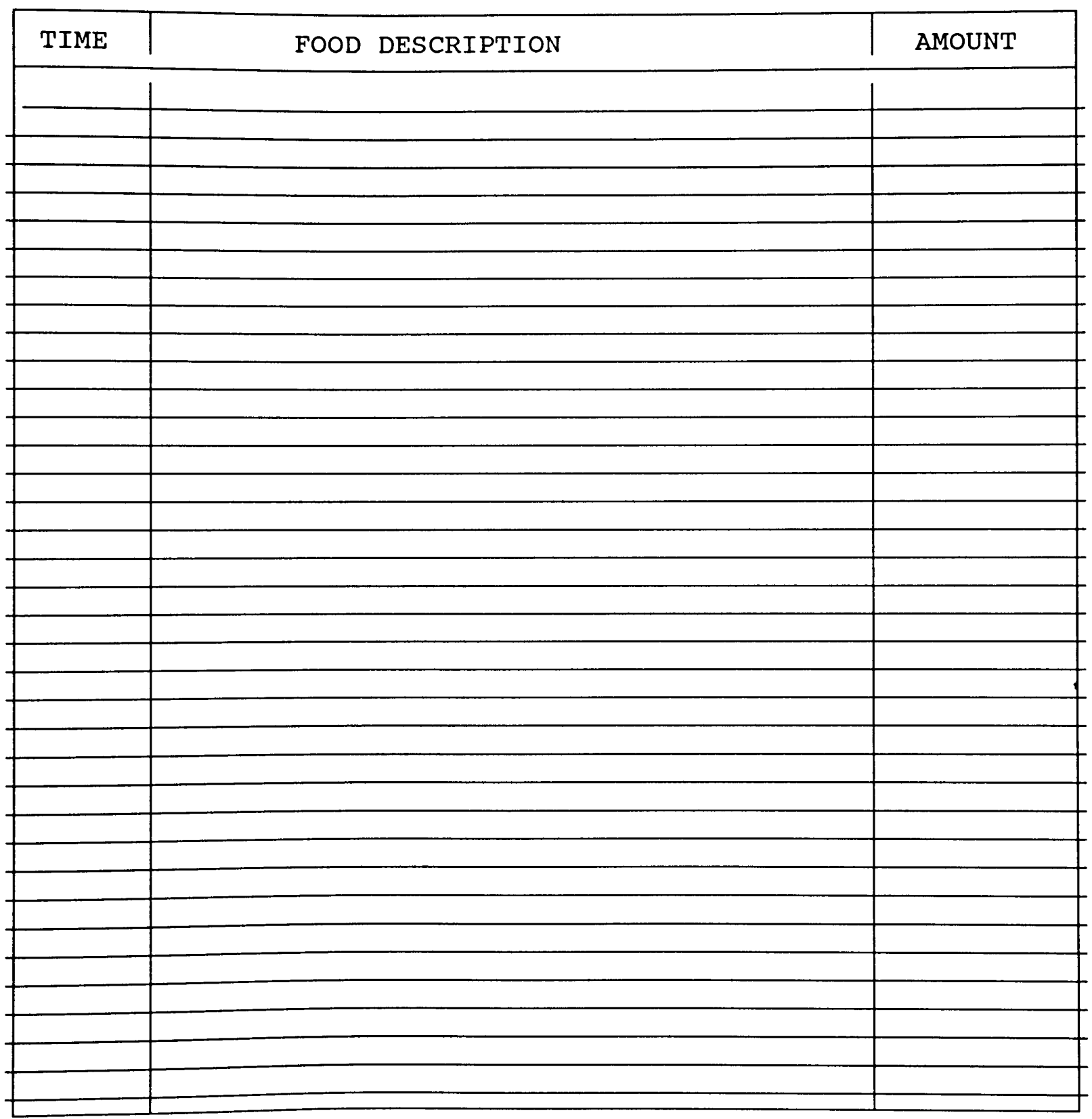


* WAS THIS A USUAL INTAKE?

Yes

No COMMENTS

* DO YOU TAKE ANY SUPPLEMENTS?

Yes

If you do, what type of supplements do you take, in what amounts and frequency?

\begin{tabular}{|l|l|l|}
\hline Type & Amount & Frequency \\
\hline & & \\
\hline & & \\
\hline & & \\
\hline & & \\
\hline & & \\
\hline
\end{tabular}

* DO YOU USUALLY DRINK ANY FLUID DURING THE DAY (water, sodas, diet sodas, alcoholic beverages, ...)? No No If you do, what type of fluids do you drink and in what amounts?

\begin{tabular}{|c|c|}
\hline Type & Amounts \\
\hline & \\
\hline & \\
\hline & \\
\hline & \\
\hline & \\
\hline
\end{tabular}

* DO YOU TAKE ANY DRUGS (prescribed and other)? Yes No

If you do, what type of drugs do you take, in what amounts and frequency?

\begin{tabular}{|c|c|c|}
\hline Type & Amounts & Frequency \\
\hline & & \\
\hline & & \\
\hline & & \\
\hline & & \\
\hline & & \\
\hline
\end{tabular}




\section{APPENDIX B. QUESTIONNAIRE}

True or False: Please circle $\mathbf{T}$ if you think that the statement is True or $\mathbf{F}$ if you think it is False

1. My diet will influence the course of my disease.

$\mathrm{T} / \mathrm{F}$

2. A diet, if seriously followed, could cure me. $\mathrm{T} / \mathrm{F}$

3. A diet, if seriously followed, could alleviate the symptoms I experience or increase my comfort?

$T / F$

4. I should increase my total caloric intake.

$T / F$

5. I should increase my total protein intake.

$\mathrm{T} / \mathrm{F}$

6. I should take a multivitamin/mineral pill daily that would provide about $100 \%$ of the RDA.

7. I should have at least 3 meals and 2 snacks. $\mathrm{T} / \mathrm{F}$

8. If I follow a vegetarian diet, I should worry about my intake of calories, protein, vitamin $\mathrm{B}_{12}$ and iron.

9. The Dr. Berger's Immune Power Diet will keep me well. $\mathrm{T} / \mathrm{F}$

10. The Maximum Immunity Diet will cure AIDS.

$\mathrm{T} / \mathrm{F}$

11. The Macrobiotic diet will keep me healthy. $\mathrm{T} / \mathrm{F}$

12. Any diet is worth being tried. $\mathrm{T} / \mathrm{F}$

13. A good nutritional status will enhance the benefits from other therapies.

14. Nutrition has nothing to do with my disease. $\mathrm{T} / \mathrm{F}$

15. Some foods are dangerous to me because of my decreased immunity.

16. Some foods will strengthen my immune system. $\mathrm{T} / \mathrm{F}$

17. If I starve myself, I will starve the virus too. 
18. I can eat ANY food.

19. By thoroughly washing raw, fresh foods, I decrease the risk of contamination.

20. Megadoses of vitamins and minerals are good for me.

21. Rice and beans is a good food combination because it provides a good source of vegetable protein.

22. I should have around $8 \mathrm{oz}$. of protein food each day (meat, fish, chicken, ham, egg,...)

23. Skim milk provides the same vitamins and minerals as whole milk, but whole milk provides more energy.

24. I should eat as much as I can while feeling well to compensate for times when I don't feel like eating.

25. Hamburger, hot dogs, ice cream, French fries, sodas, chocolate, potato chips, fried foods, sweets, and other so called "junk foods" are OK to eat.

To limit loss of nutrients during food preparation, I should limit as much as possible:

26. the peeling of fruits and vegetables

27. the amount of water used to cook the food

28. the cooking length of time

29. the period of storage of fresh foods

30. the exposure to heat, light, and air 


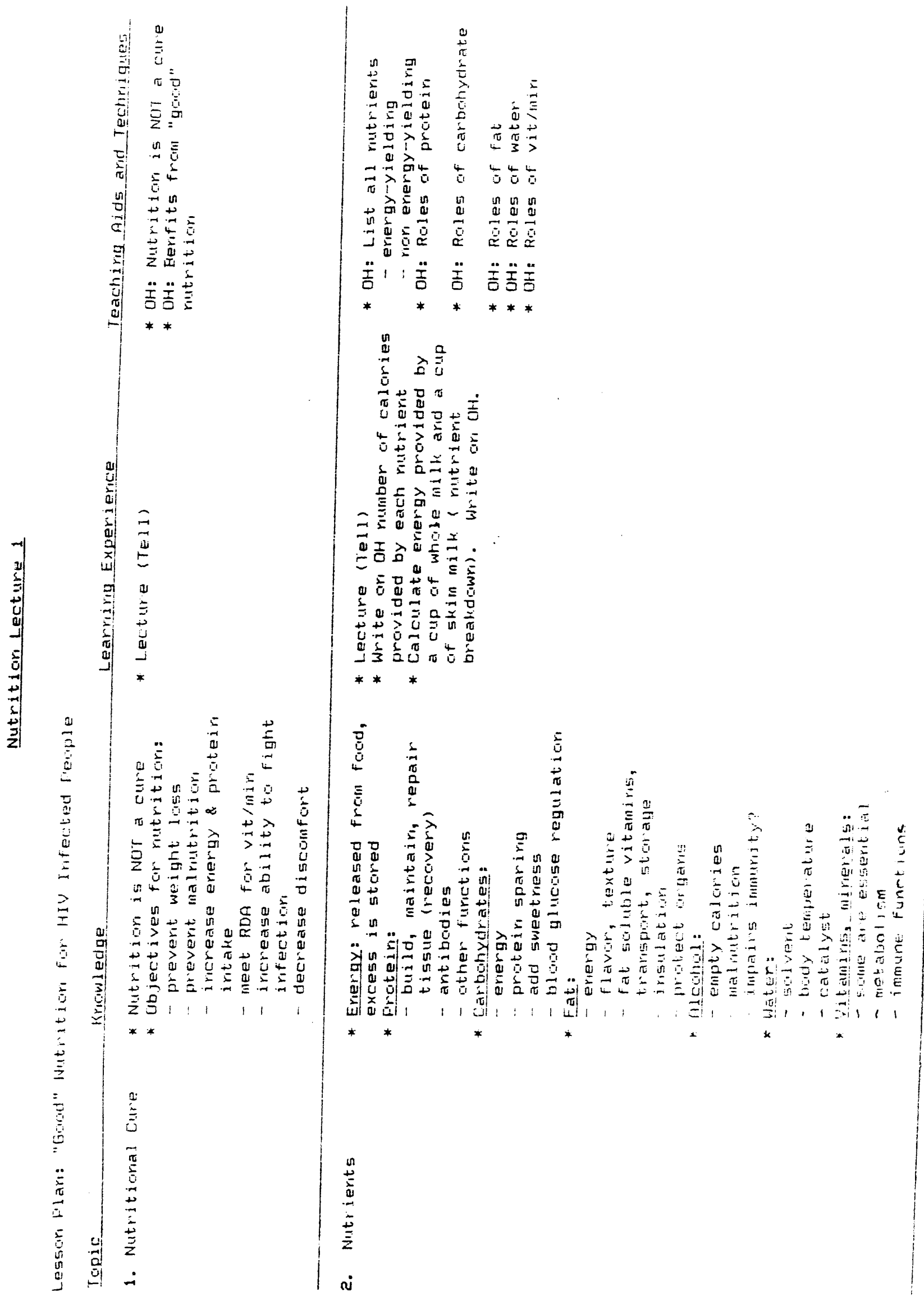




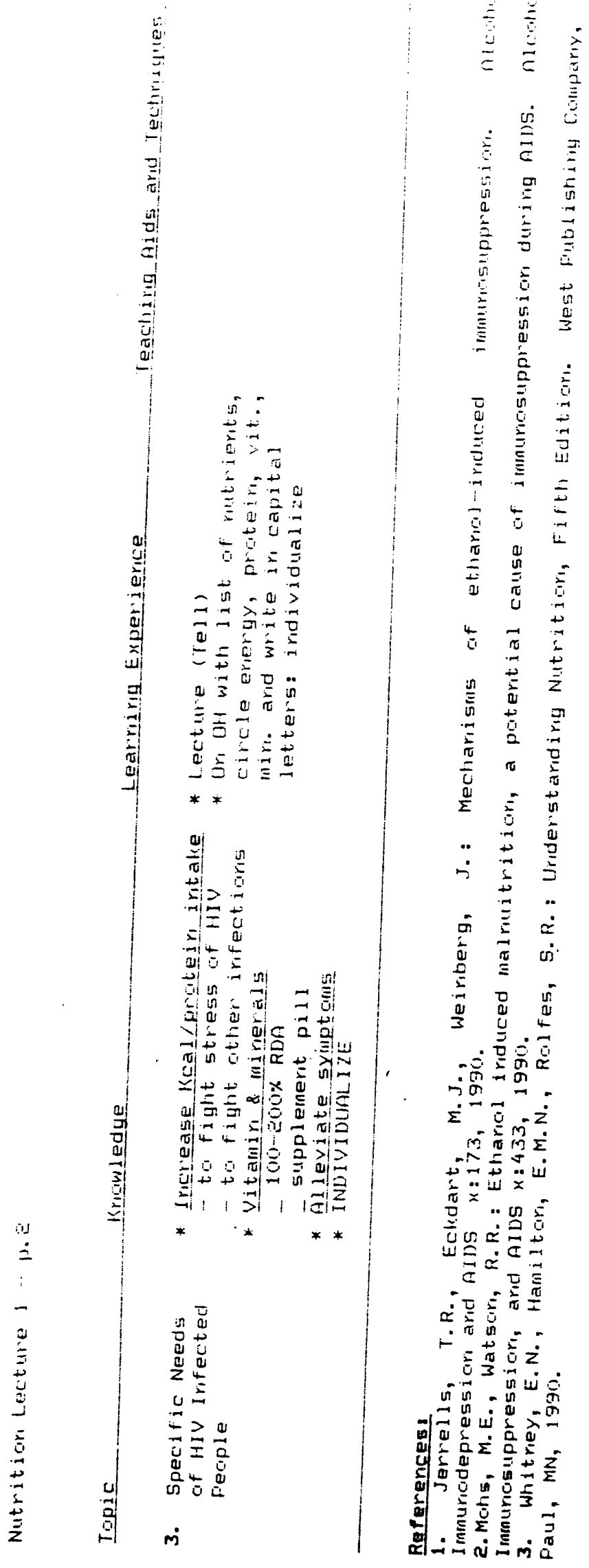




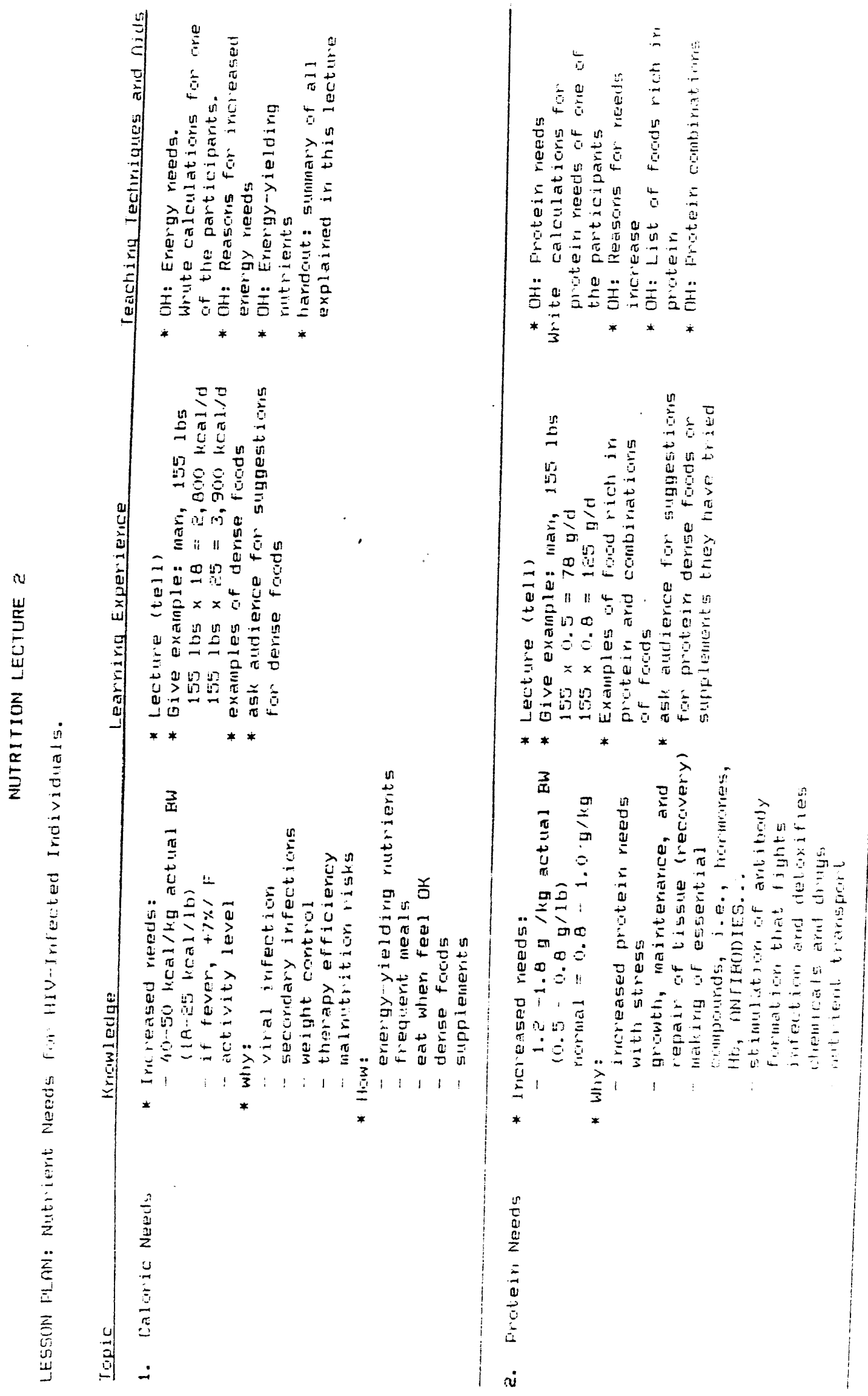




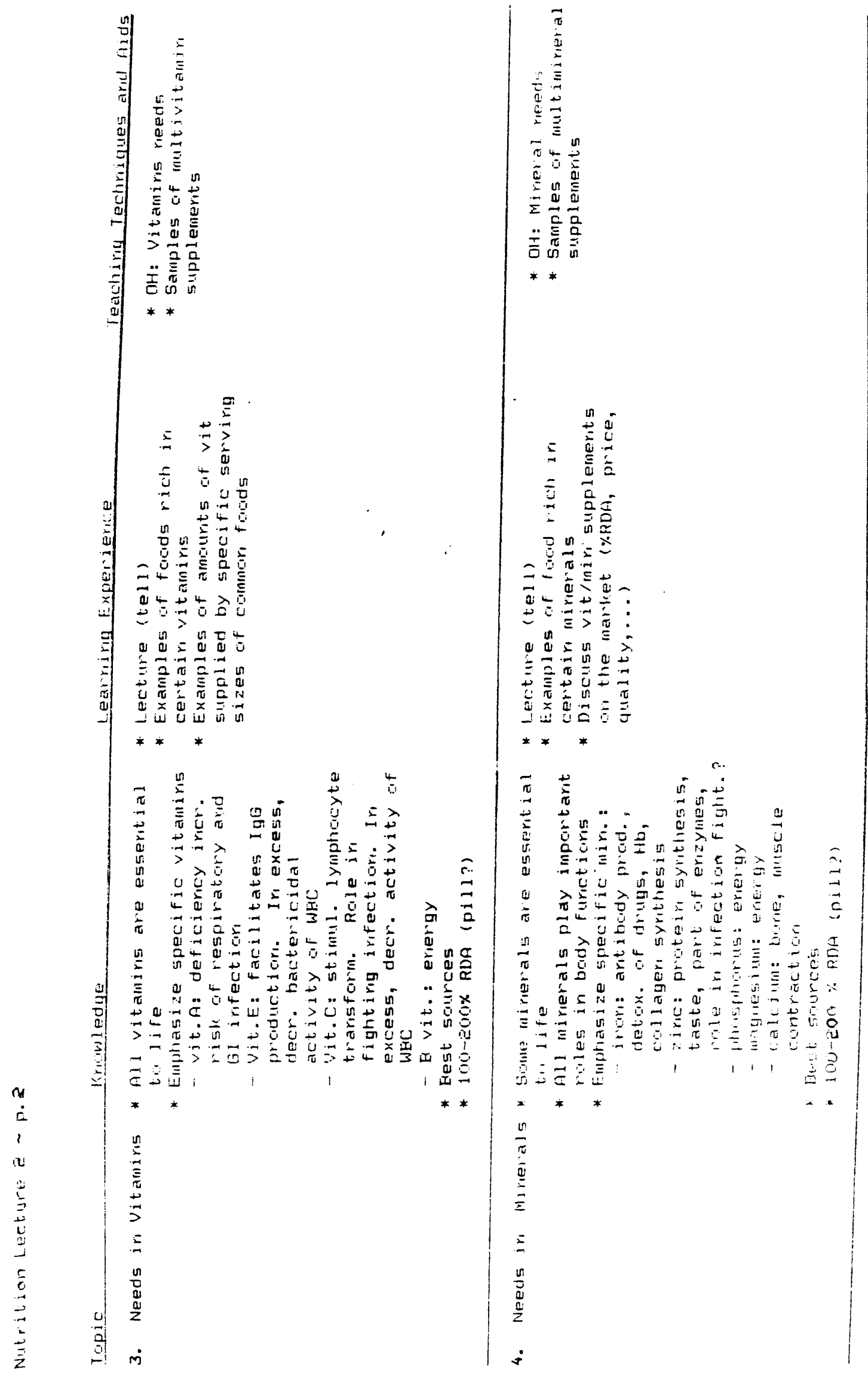




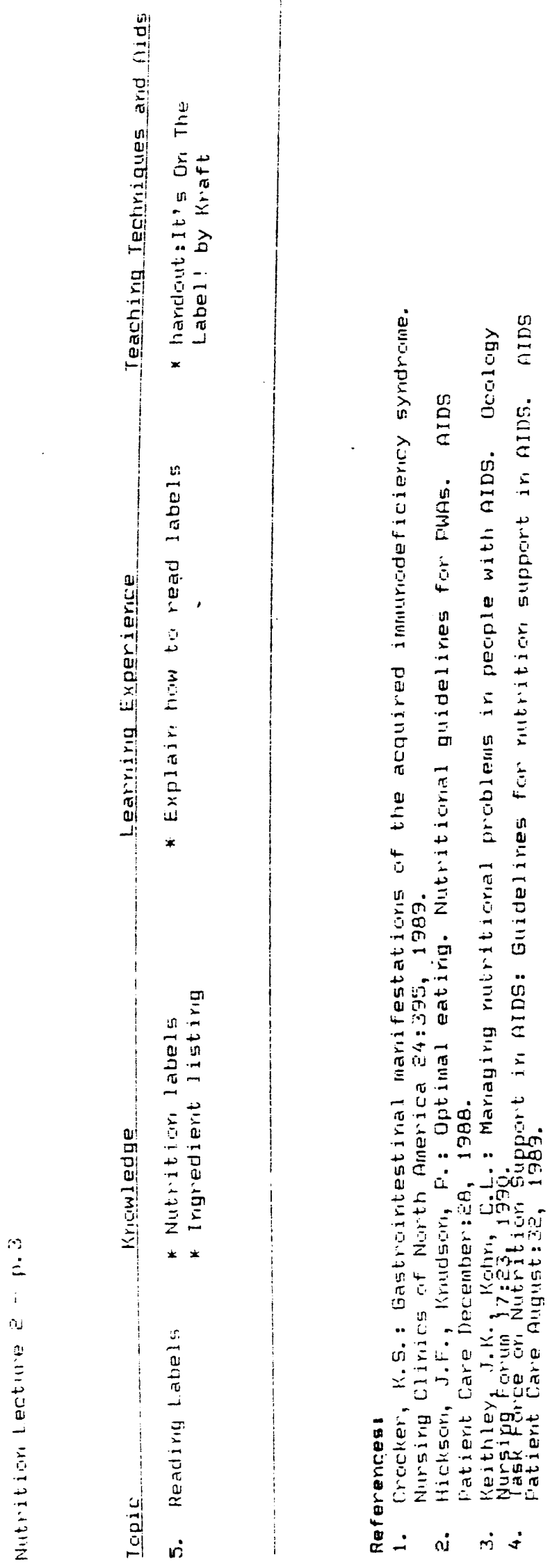




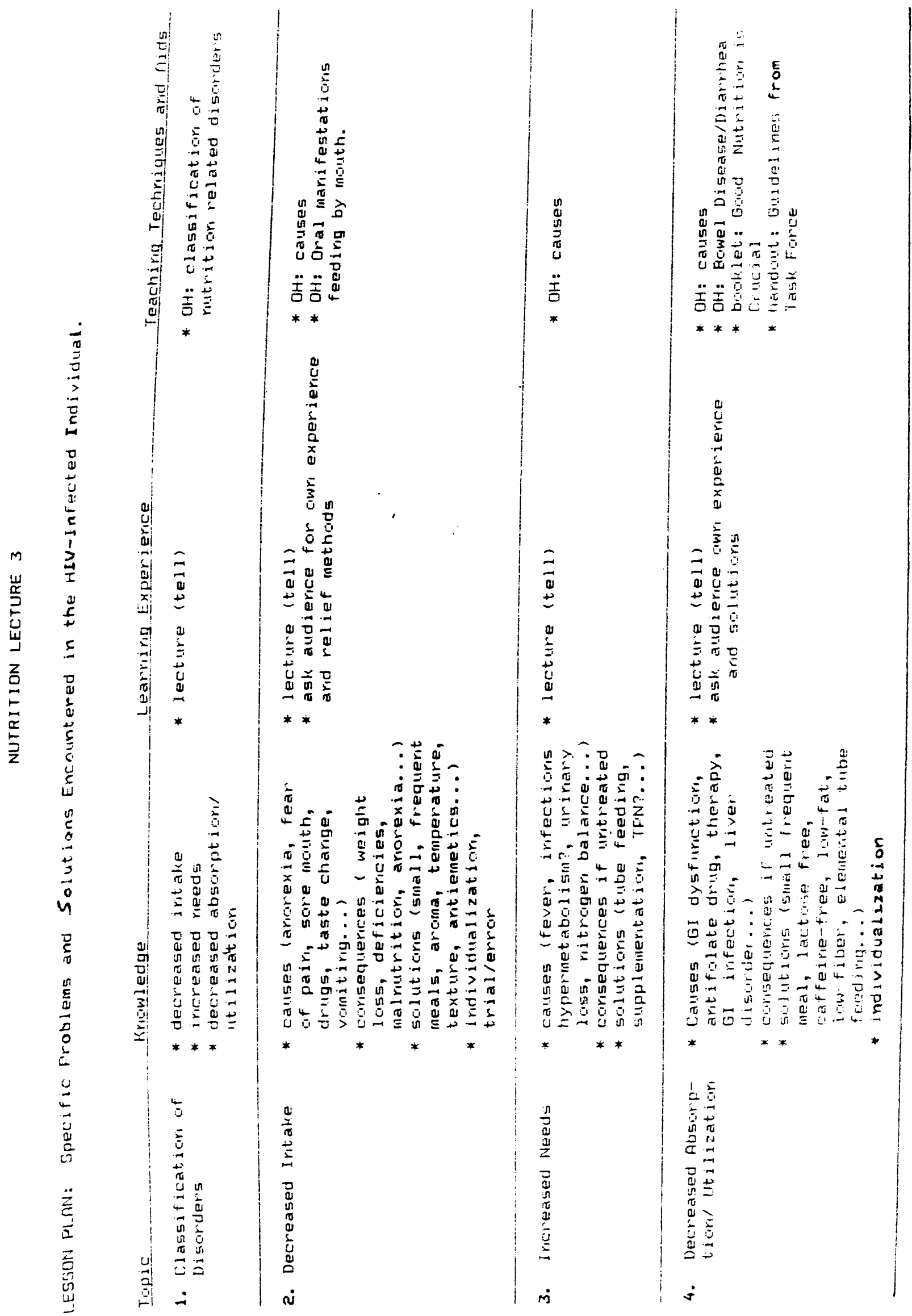




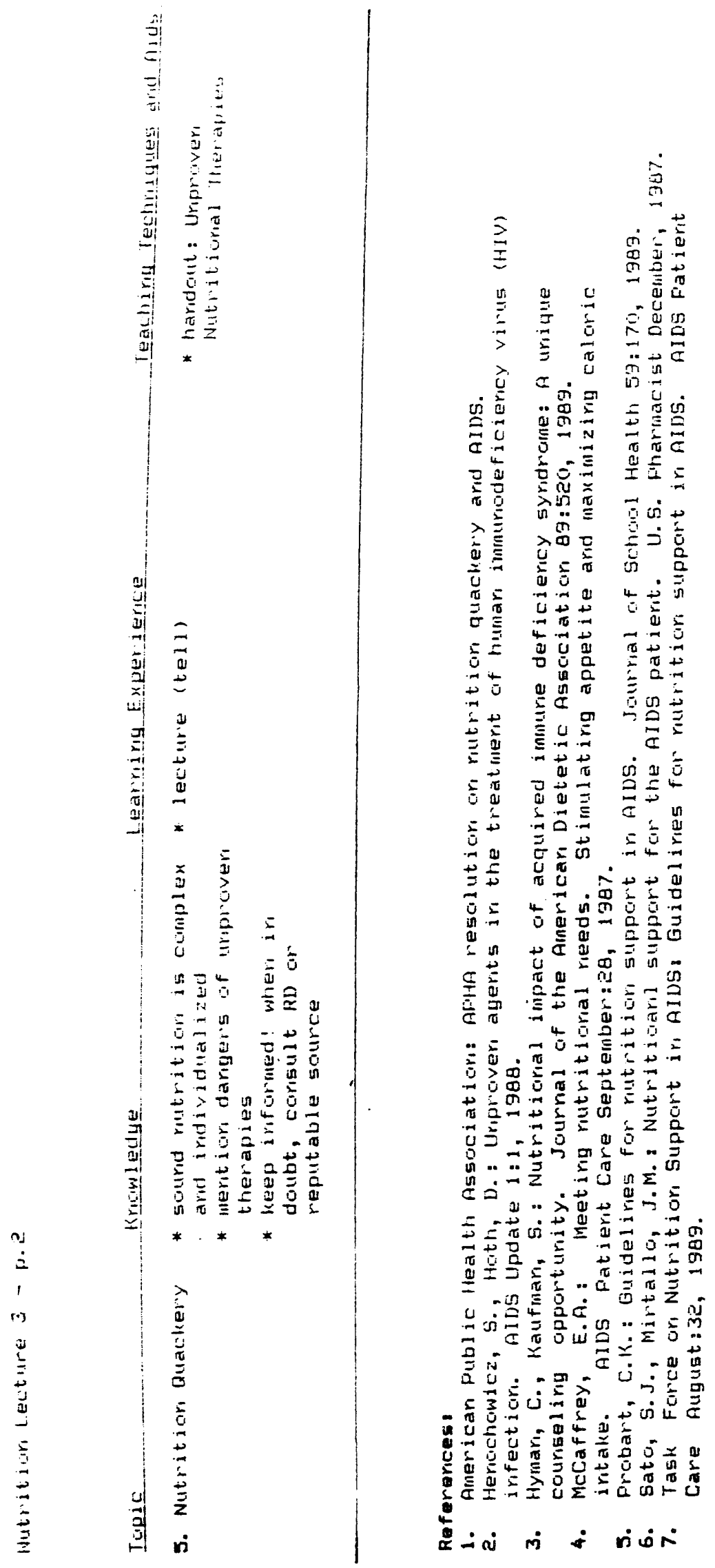




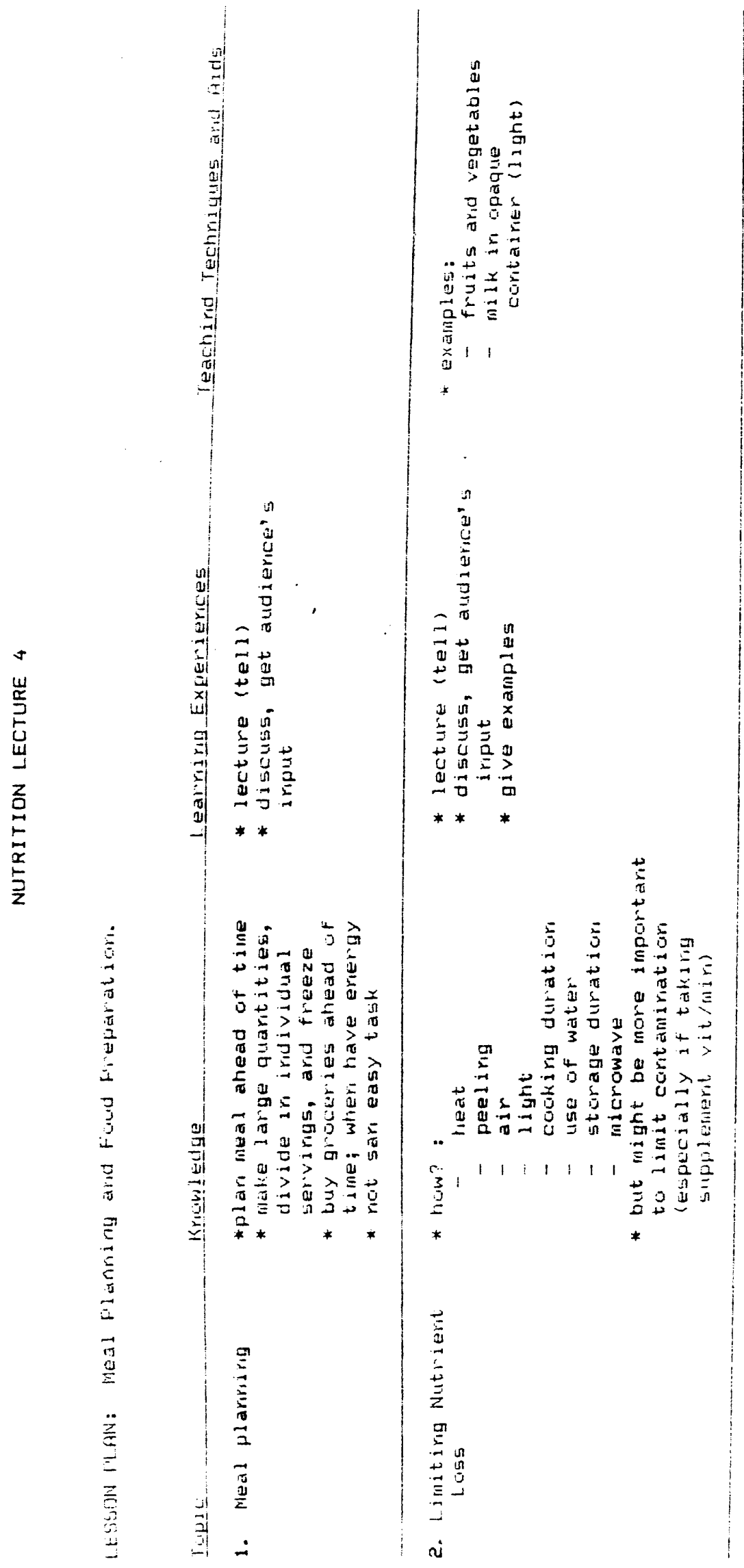




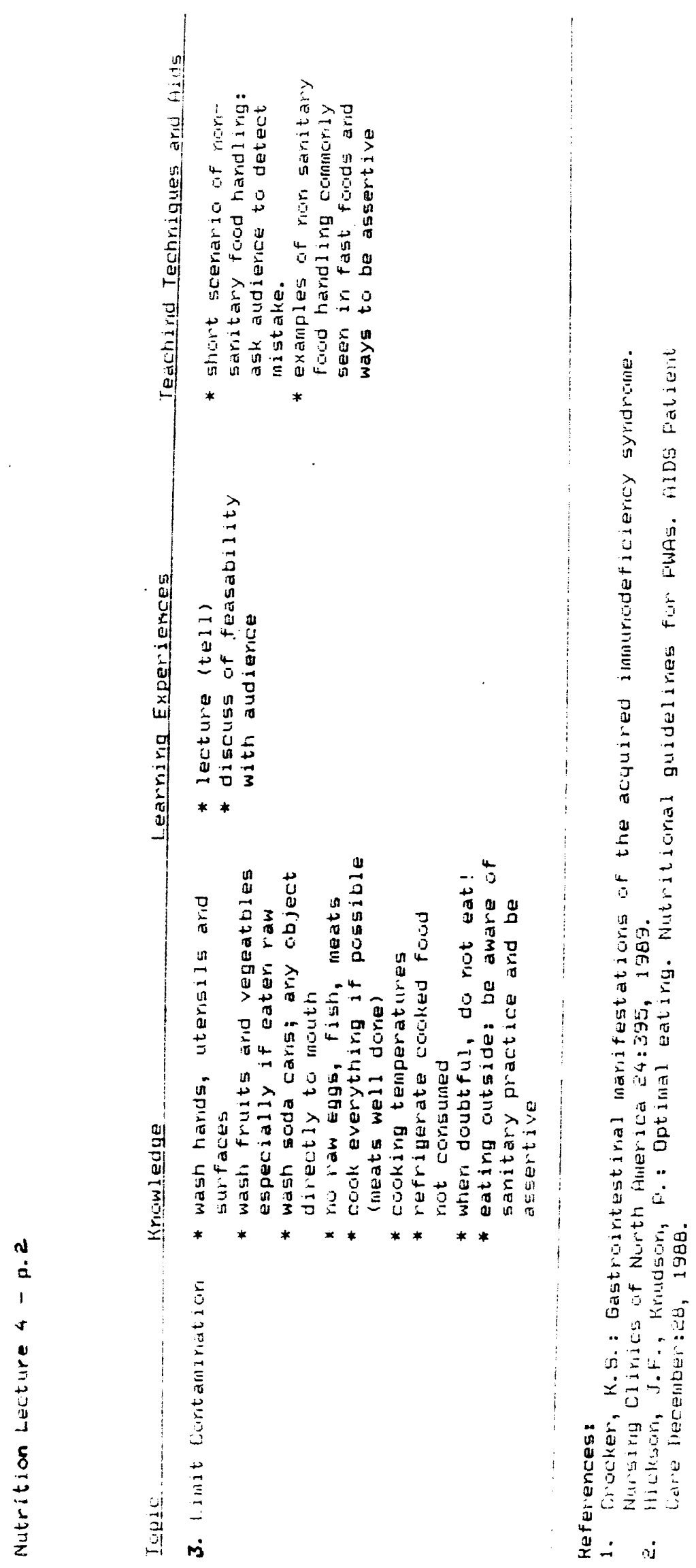




\section{Appendix D. List of Samples Used for Nutrition Lecture 2.}

* Kellogg's frosted flakes of corn.

* Creamette Italian style enriched spaghetti.

* Holsum Country Health butter loaf enriched bread.

* Chef Boyardee Microwave Meals beef ravioli in tomato and meat sauce.

* Fancy Albacore Star Kist solid white tuna in spring water.

* Fancy Albacore Star Kist solid white tuna in pure vegetable oil.

* Campbell's split pea with ham and bacon soup.

* Publix Real Wisconsin Cheese Bar. Shredded low moisture partskim mozzarella cheese.

* Romanoff; MBT; Instant chicken flavored broth.

* Sustacal; Mead Johnson; Nutritionally complete liquid food. ready to use. Lactose-free. vanilla flavored artificial flavor. 240 Calories.

* Meritene powder; Sandoz Nutrition; Milk chocolate artificial flavor. Protein vitamin mineral food.

* Sandoz Nutrition; resource Plus; Complete balanced nutrition. 355 Calories. High calorie liquid ready to serve. Creamy vanilla artificial flavor. Lactose-free.

* Publix. High potency A to $\mathrm{z}$ multivitamin multimineral formula with beta carotene. 100 tablets.

* Publix. Daily multivitamins plus iron. 100 tablets.

* Centrum. high potency multivitamin multimineral formula from A to Zinc with beta carotene. 60 tablets. \$6.49.

* One a day. Essential. 11 essential vitamin with beta carotene. 100 tablets. $\$ 5.29$. 


\section{Nutrient intakes of:}

Energy (Kcal), protein ( $g$ ), fat $(g)$, carbohydrates $(g)$, fiber $(\mathrm{g})$, cholesterol (mg), iron (mg), sodium (mg), calcium (mg), phosphorus (mg), vitamin A (IU), thiamin (mg), riboflavin (mg), vitamin C (mg), potassium (mg), zinc (mg), niacin (mg), vitamin B6 (mcg), vitamin B12 (mcg), and folacin (mcg).

\section{for:}

- each food item in amount used

- breakfast totals

- noon meal totals

- evening meal totals

- snacks totals

- daily totals

- percent of recommendations

Also featured:

- actual percentage of calories distribution

- percentage of calories from alcoholic beverages. 